\title{
Numerous paradoxes explained by bandwagoning
}

\author{
Idan S. Solon \\ University of Central Florida, Burnett School of Biomedical Sciences
}

Orlando, Florida, United States 32816

Correspondence: IdanSolon@gmail.com 


\begin{abstract}
Background: Solon (2019) introduced genetic bandwagoning in a very general sense: A variant sequentially 1) evaluates its holder's quality and 2) induces its holder to relinquish resources if the holder's quality is low. Here, I introduce a more complex form of bandwagoning in order to account for a series of phenomena considered "paradoxical" by scientists specializing in their literatures: a) depression, b) differential nurturing, c) honest signaling of quality, d) reproductive suppression, e) stress-induced anthocyanins, and f) hormesis.
\end{abstract}

These literatures are characterized by the following findings:

1) Low-quality individuals incur a cost against reproductive success compared to higher-quality individuals.

2) Individuals not (yet) identified as low-quality incur a cost against their ability to survive predators and/or parasites compared to individuals that have already been identified as low-quality.

3) Females incur a cost against reproductive success compared to males.

4) Males incur a cost against their ability to survive predators and/or parasites compared to females.

5) If conditions are challenging, individuals gain in both reproductive success and their ability to survive predators and/or parasites compared to less challenging conditions; however, too-challenging conditions detract from both.

For each literature, at least one of these findings is unaccommodated by existing theory when considered in the context of that literature. Despite existing theory, these patterns are remarkably persistent.

Question: Can paradoxes fitting these patterns be explained by genetic bandwagoning theory?

Conclusion: Here, reservation is introduced as a form of bandwagoning in which a bandwagoning variant induces its holder to reserve from (i.e., withhold) some of its ability to survive parasites or predators. Reservation would occur for the purpose of assessing a holder's quality when conditions are sufficiently unchallenging that few individuals are chronically stressed, so it is otherwise difficult to evaluate a holder's quality. If the holder is subsequently killed, wounded, or infected, then it is identified as lacking the quality that would allow its descendants to survive more challenging conditions. The holder loses some or all of its resources as a direct consequence of the very death, wounding, or infection that identified its low quality. That is, in reservation, the two steps of bandwagoning are accomplished simultaneously. (This way of bandwagoning is distinguished from when the two 
steps are accomplished sequentially, which is termed resonation.) Reservation shares numerous premises with Zahavi’s handicap principle.

If conditions are challenging, individuals would downregulate reservation and also be less likely to forego resources through resonation (which accounts for (5)). Additionally, a bandwagoning variant would likely evolve to vary the reservation it induces from holder to holder as a hedge against the possibility that conditions suddenly turn severe before it can adjust the reservation. Individuals already identified as low-quality would downregulate reservation (which accounts for (2) above) and would instead forego resources through resonation (which accounts for (1)). Additionally, females would downregulate reservation (which accounts for (4)) and, as a consequence, surviving females are more likely than surviving males to forego resources through resonation (which accounts for (3)).

Keywords: depression; nurturing; honest signaling; reproductive suppression; anthocyanins; hormesis 


\section{Introduction}

Solon (2019) introduced the concept of genetic bandwagoning. Genetic bandwagoning occurs when a variant (e.g., allele, epigenetic mark, or some combination thereof): a) evaluates the quality ${ }^{1}$ of its holder and b) induces the holder to relinquish reproductive opportunities and other resources if the holder's quality is low.

In Solon (2019), genetic bandwagoning was introduced in a very general sense. Here, I argue that a more specific form of genetic bandwagoning corresponds to a set of findings in numerous literatures (see sections 3 through 8).

The literatures are consistently characterized by the following findings:

(1) Lower-quality individuals incur a cost in obtaining reproductive success.

(2) Individuals that have not been identified as lower-quality incur a burden in surviving parasites and/or predators.

(3) Males incur a burden in surviving parasites and/or predators.

(4) Females incur a cost in obtaining reproductive success.

(5) In response to indications that conditions ${ }^{2}$ are challenging, individuals improve in surviving parasites and/or predators.

(6) In response to indications that conditions are challenging, individuals improve in reproductive success.

In addition, at least one of these findings in each literature is considered paradoxical by at least some biologists specializing in it because it cannot be reconciled with prevailing theory.

In section 2, I review how indications of an organism's low quality are distinguishable from indications of challenging conditions. In sections 3 to 8, these literatures are reviewed, with a focus on the six patterns listed above. In sections 9 and 10, I explain how genetic bandwagoning theory can account for these findings.

\section{Stress: Due to lower quality or challenging conditions?}

\footnotetext{
${ }^{1}$ Quality is used here in the same "good genes" sense as in Solon (2019): the degree to which an individual has heritable traits that offer it advantages in obtaining prey, territory, and mates and in surviving predators and parasites.

${ }^{2}$ See section 2 regarding what is meant by challenging conditions.
} 
The degree to which an organism has experienced stress is an important indicator of its quality, so that makes it a topic of focus here. Stress can be experienced physically and/or psychologically and encompasses a broad class of phenomena. Virtually every indicator that an organism is low-quality is a form of stress ${ }^{3}$. However, not every form of stress is an indicator of low quality. This is because an organism's stress levels are contingent upon both individual phenotypic variation and spatiotemporal environmental variation (Ram and Hadany, 2016). That is, some potential sources would afflict only individuals that lack the advantageous variants that would allow them to manage these sources, while other potential sources of stress would afflict nearly every individual in a population that is exposed to them. Stress due to the former sources indicates the individual is lower-quality compared to conspecifics. Stress due to the latter sources does not because most or all individuals would be stressed if exposed. Rather, stress due to the latter sources is more of an indication that conditions facing the organism are challenging at that location and time.

Certain psychological stressors are more of an indication that an individual is low-quality compared to conspecifics. For example, an individual is indicated to be low-quality if it becomes rejected by a parent or potential mate or if it is bullied by a dominant individual (Georgiev et al., 2015). These are situations in which an individual experiences psychological stressors in response to being lower quality than other individuals.

On the other end of the spectrum are some physical stressors such as an organism's response to predator odor and physical exercise. Both of these stressors are suggestive of a predator threat in the vicinity. (Physical exercise can simulate predator evasion, as physical activity can be both a cause and an effect of an increased predator threat; Sih et al., 2004). In the absence of wounding, both of these stressors indicate more challenging conditions rather than the stressed organism's lower quality because it would have been unusual in evolutionary time for organisms to have genes enabling them to avoid the stressor - that is, avoid a predator without sensing it or engaging in physical activity.

However, most physical stressors can indicate either the organism's low quality compared to conspecifics or challenging conditions, depending upon context. For example, stressors such as hunger, infection, and wounding are caused by natural enemies (respectively, prey, parasites, and predators) that can rapidly evolve, so there is often

\footnotetext{
${ }^{3}$ There are exceptions, such as those considered in Solon (2019): High chronological age and low genetic heterozygosity are both indicators of lower quality.
} 
genetic variation in a population for traits used against these natural enemies. Consequently, hunger, infection, or wounding can indicate lower quality. However, such indications are dependent upon the context in which it occurs. If honest signaling (Andersson, 1994) or other observation suggests that neighbors are also afflicted, this would be more indicative of challenging conditions. However, the degree of exposure to parasites and predators can vary from one location to another. Therefore, an evaluation of an individual's quality is also modulated by indications about the magnitude of parasite or predator exposure it has experienced: the higher the exposure, the higher the individual's quality.

\section{Depression}

\subsection{Background}

Chronic bouts of stress lead, in many species, to anhedonia; diminished libido; and sadness, self-loathing, and selfneglect (Seligman, 1975; Weiss, J. et al., 1982; Sapolsky, 1998; Austin et al., 2001; Franklin et al., 2012; Anders et al., 2013; Sun et al., 2013). These symptom clusters indicate depression in humans (Austin et al., 2001; Anders et al., 2013; Sun et al., 2013) and learned helplessness in other species, including cats, dogs, rats, fish, primates, and insects (Seligman, 1975; Weiss, J. et al., 1982; Sapolsky, 1998; Franklin et al., 2012). In humans, these symptoms often carry considerable costs, including disability and risk of suicide and other causes of mortality (Caspi et al., 2003; Hagen, 2003; Nestler, 2012). Depression is also associated with increased physiological resistance against parasites (Kinney and Tanaka, 2009; Anders et al., 2013; Raison and Miller, 2013).

\subsection{Paradox}

There probably were mutations in evolutionary time that allowed organisms to avoid the evidently-costly depressive moods in response to stress. However, depression is prevalent, even during ages at which natural selection is strong (Medawar, 1952). Consequently, depression has long been considered an evolutionary paradox (Hagen, 2003; Nettle, 2004; Kinney and Tanaka, 2009; Varga, 2012; Raison and Miller, 2013).

In an additional paradox, females are consistently found to experience depression at higher rates (Hopcroft and Bradley, 2007).

de Catanzaro's $(1981,1984)$ theory of depression holds that depression, with the associated suicidal ideations, occurs to increase inclusive fitness by offering a person's resources to more productive kin. His work was discussed 
in Solon (2019) as consistent with genetic bandwagoning in a very general sense. However, de Catanzaro's theory does not account for the enhanced parasite resistance that is associated with depression.

A set of recently-advanced hypotheses holds that depression was selected in conjunction with the prevention of infection by parasites and pathogens, in order to encourage energy preservation and solitude during times of high parasite risk (Kinney and Tanaka, 2009; Anders et al., 2013; Raison and Miller, 2013). Such a view dates to at least Hart (1988), but has become popular more recently due to evidence suggesting genetic and physiological links between parasite resistance and depression (Anders et al., 2013; Raison and Miller, 2013). However, while many causes of depression might have, historically, suggested an increased infection risk, other common ones (e.g., the death of kin or the loss of a mate without combat) may not have imposed enough of an infection risk to make depression beneficial to the organism or to kin, especially since kin can be adversely affected by a person's depression (Ramchandani et al., 2005; Shen et al., 2016). That many forms of chronic stress precipitate a costly depressive response tailored to parasite resistance seems very inefficient, which contrasts with the precision associated with other aspects of the stress response (Sapolsky, 1998). Indeed, depression is caused by numerous non-infectious diseases, even if the person is unaware that he or she is diseased (Yirmiya et al., 1999; Dowlati et al., 2010; Irving and Lloyd-Williams, 2010; Parker, G. and Brotchie, 2017; Pryce and Fontana, 2017). Additionally, depression would be a costly way of exerting a preference for solitude. As non-depressed people can exhibit a preference for solitude (Burger, 1995), there probably could have been mutations over evolutionary time scales that would have led a sick person to prefer solitude without requiring that person to incur the costs of self-loathing.

\subsection{Lower-quality individuals incur a cost in obtaining reproductive success}

Depression appears to be a cost against reproductive success that occurs in response to stress. However, not all stressors cause depression. For example, physical exercise does not (Craft and Perna, 2004; Stathopoulou et al., 2006; Cooney, G. et al., 2013; Schuch et al., 2016; but see Krogh et al., 2017). Physical exercise is a stressor that is more indicative of challenging conditions (see section 2). The stressors that commonly cause depression include rejection by a parent, bullying by a conspecific, rejection by a mate, infectious or noninfectious disease, and a parent's depression from the same sources (Yirmiya et al., 1999; Widom et al., 2007; Dowlati et al., 2010; Kaltiala-Heino and Frojd, 2011; Anders et al., 2013; Raison and Miller, 2013; Nestler, 2014). These stressors are generally indicative of the stressed individual's low quality (see section 2). 


\subsection{Individuals that are not identified as lower-quality incur a burden in surviving parasites and/or predators}

Depression is a response to stressors that indicate lower quality (section 3.3). Since individuals that are not identified as lower-quality experience depression less, they also have less of the physiological resistance to parasites that is associated with depression (see section 3.1).

\subsection{Males incur a burden in surviving parasites and/or predators}

Males are significantly less likely to develop depression than females (Nolen-Hoeksema, 1990; Hopcroft and Bradley, 2007; Andrews and Thomson, 2009; Seedat et al., 2009). Therefore, males have less of the physiological resistance to parasites that is associated with depression, which helps explain why males have significantly higher parasite loads than females (Folstad and Karter, 1992; Klein, 2000).

\subsection{Females incur a cost in obtaining reproductive success}

The female incidence of depression is higher than males (see section 3.5). This is a paradox in consideration of theories holding that depressive mood occurs to promote isolation in order to prevent infection (Kinney and Tanaka, 2009; Anders et al., 2013; Raison and Miller, 2013). These latter theories would predict males to be more susceptible to depression than females, since, in evolutionary time, they were more likely to participate in hunting, escaping predators, and fighting conspecifics — activities implicated by Raison and Miller (2013) in imposing infection risk.

\subsection{In response to indications that conditions are challenging, individuals improve in surviving parasites and/or} predators

Physical exercise simulates challenging conditions (see section 2) and moderate physical exercise is found in multiple species to raise resistance to infection (Davison et al., 2014; Bortolini et al., 2016), though exercise that is too strenuous increases susceptibility to infection (Brenner et al., 1994; Nieman, 1998; Shephard, R., et al., 1999).

\subsection{In response to indications that conditions are challenging, individuals improve in reproductive success}

Numerous meta-analyses have found that physical exercise reduces depression incidence (Craft and Perna, 2004; Stathopoulou et al., 2006; Cooney, G. et al., 2013; Schuch et al., 2016; but see Krogh et al., 2017). The diminished depression that occurs with physical exercise is also more difficult to explain with a theory that depression occurs to reduce the risk of infection spreading, as it simulates hunting, escaping predators, and fighting conspecifics—all behaviors assumed 
by Raison and Miller (2013) to carry the most significant infection risk. This is another paradoxical finding of this literature that fits the pattern outlined in section 1.

\section{Differential nurturing}

\subsection{Background}

In numerous rodents and primates, higher levels of maternal nurturing (e.g., licking and grooming) lead to more growth (Denenberg and Karas, 1959; Field, T. et al., 1986; Schanberg, 1995; Field, T., 1998), greater cognitive function and memory (Field, T., 1998; Korosi and Baram, 2009; Zhang, T.Y. and Meaney, 2010), higher alertness (Field, T. et al., 1986; Field, T., 1998), greater behavioral maturity (Field, T. et al., 1986), and lower mortality risk (Denenberg and Karas, 1959; Field, T. et al., 1986). Alternatively, lower levels of maternal nurturing lead to a depressed-like phenotype, which includes depression (Franklin et al., 2010, 2011; Weiss, I. et al., 2011), anxiety (reviewed in Korosi and Baram, 2009; Weiss, I. et al., 2011), and greater tendencies to resign to stressful sources (Nestler, 2012). Despite the costs incurred by offspring that are nurtured less than others, mothers that are chronically stressed reduce nurturing across the aggregate of their offspring (Bosch et al., 2007; Zhang, T.Y. and Meaney, 2010; Heiming et al., 2011; Mansuy et al., 2013). A mother's nurturing practices tend to remain consistent through her lifetime and her offspring are likely to impart the same levels of nurturing to their offspring that they received from their mother-within-lineage consistency of maternal nurturing which is mediated epigenetically (Meaney, 2001; Zhang, T.Y. and Meaney, 2010; Mansuy et al., 2013; Drury et al., 2016).

\subsection{Paradox}

The leading evolutionary explanation for reduced nurturing by stressed mothers is that it acts as a signal to offspring regarding the level of vigilance required in the environment, particularly versus predators (Champagne et al., 2003; Pittet et al., 2012; Drury et al., 2016). However, maternal effects (e.g., licking, grooming) are dependent upon the father's experiences, even if the offspring share the same mother (and evidently the same formative environment). Even in the postpartum absence of fathers, offspring of fathers subjected to social defeat stress are induced via maternal effects to exhibit a depressed-like phenotype (Dietz et al., 2011; Dietz and Nestler, 2012), while offspring of enriched-reared fathers are nurtured more than other offspring (Mashoodh et al., 2012). Additionally, exposure to predator odor during gestation or postnatally has often been found to stimulate postpartum maternal affection (McLeod et al., 2007; Coutellier and Wurbel, 2009; Mashoodh et al., 2009; Ayers et al., 2016; St-Cyr et al., 2018; but see St-Cyr and McGowan, 2015 for less nurturing by predator-odor-exposed mothers and see St-Cyr et al., 2017 for no differences in nurturing). These empirical findings are the opposite 
of what would be expected if reduced nurturing were solely intended to increase vigilance toward predators (Dickins and Rahman, 2012). Furthermore, the cooccurrence of hypotheses holding that depression is solely to prevent the transmission of infections (section 3) and hypotheses holding that a depressed-like phenotype is solely to maintain vigilance against predators (this section) lends credibility to the notion that these behaviors are not tailored to either purpose.

Work by Sapolsky (1998) and Suomi (1997) suggests that reduced maternal nurturing results in offspring that become subordinates in groups and, therefore, achieve lower reproductive success. They independently documented what they considered inefficient stress responses in, respectively, baboons and rhesus monkeys. This condition, which Sapolsky (1998) and Suomi (1997) each considered maladaptive, is both a cause and an effect of reduced maternal nurturing.

\subsection{Lower-quality individuals incur a cost in obtaining reproductive success}

The costs associated with lowered nurturing include less growth, lowered cognitive function, more depression, and higher mortality risk. In experiments, the types of chronic stress inflicted upon parents that have caused diminished nurturing to offspring have typically been bullying or restraint stress (Smith et al., 2004; Champagne and Meaney, 2006; Bosch et al., 2007). While restraint stress does not have a close analogue to wild conditions, stress from bullying can indicate the bullied organism's lower quality (Georgiev et al., 2015). Experimental stressors that indicate low parental quality also suggest low offspring quality because quality is, by definition, heritable.

\subsection{Individuals that are not identified as lower-quality incur a burden in surviving parasites and/or predators}

Well-nurtured individuals are less vigilant to predators (Champagne et al., 2003). Additionally, restraint stress causes increased resistance to parasites (Iwakabe et al., 1998), which is consistent with the interpretation that organisms not experiencing restraint stress do not resist parasites as well.

\subsection{Males incur a burden in surviving parasites and/or predators}

In rodents such as rats and mice, male offspring are nurtured more than female offspring (Moore and Morelli, 1979; Moore and Chadwick-Dias, 1986; Moore and Power, 1986; Alleva et al., 1989; Moore, 1995; Hao et al., 2011; Van Hasselt et al., 2012). Since nurturing causes offspring to become less capable of evading predators and resisting parasites (see section 4.4), this finding is consistent with the interpretation that males do not evade predators or resist parasites as well as females. 


\subsection{Females incur a cost in obtaining reproductive success}

Female offspring are nurtured less than male offspring (see section 4.5). Less-nurtured offspring incur reproductive costs (see section 4.1). These findings, taken together, suggest that females incur more reproductive costs from lowered nurturing.

4.7 In response to indications that conditions are challenging, individuals improve in surviving parasites and/or predators

Predator odor is suggestive of more challenging conditions. Predator odor exposure increases vigilance to predators in rodents (reviewed in Takahashi et al., 2005). Additionally, offspring exposed to predator odor during pregnancy exhibit higher levels of vigilance to predators (St-Cyr and McGowan, 2015; St-Cyr et al., 2018).

4.8 In response to indications that conditions are challenging, individuals improve in reproductive success

As predator odor is suggestive of a stronger predator presence, it indicates more challenging conditions (see section 2). Exposure to predator odor during gestation or postnatally has been found to stimulate postpartum maternal affection (see section 4.2). This means that when conditions are challenging, an offspring is less likely to receive low nurturing and its associated costs. Interestingly, postnatal exposure to predator odor enhances the offspring's spatial learning (Hacquemand et al., 2012), perhaps through higher levels of licking and grooming (Liu et al., 2000; Bredy et al., 2003; Bredy et al., 2004).

\section{Honest signaling and the susceptibility to parasites associated with sexually-selected characteristics}

\subsection{Background}

In mammals, birds, lizards, fish, and other taxa, androgens (e.g., testosterone) are evidently responsible for an association between an organism's quality and that organism's sexually-selected characteristics (e.g., strength, aggression, ornaments, songs, displays). Higher quality leads to more androgen production, which leads to more advantageous sexually-selected characteristics (Nelson et al., 1989; Folstad and Karter, 1992; Johnstone, 1995; Dong et al., 2004; Muehlenbein and Bribiescas, 2005; McGraw and Blount, 2009; Ritschard et al., 2011; Lynn et al., 2015; Fedurek et al., 2016; Weaver et al., 2017). The production of androgens also appears to cause susceptibility to parasites in many species (Roberts et al., 2004; Habig and Archie, 2015). Numerous biologists have hypothesized that these phenomena owe to a tradeoff between sexually-selected characteristics and immunity, with higher-quality organisms investing more in sex because they 
can better afford to sacrifice immunity (Folstad and Karter, 1992; Groothuis et al., 2005; Muehlenbein and Bribiescas, 2005). The tradeoff suspected is typically energetic (Groothuis et al., 2005), though other resources have been suggested (Muehlenbein and Bribiescas, 2005).

\subsection{Paradoxes}

In particular, two paradoxes in the literature on sexually-selected characteristics apply.

1) Why do some sexually-selected exhibitions honestly reflect quality despite the potential for mutations to evolve that would allow dishonestly advantageous exhibitions?

Many ornaments and other signals do not appear at all costly to produce (Husak and Swallow, 2011; Emlen et al., 2012; Simons et al., 2015), which raises the question: Why are they not faked? That is, why are sexually-selected characteristics not decoupled from the androgen production, which would allow the advantageous characteristics to be exhibited even if the organism downregulates androgen production?

For example, in birds and fish, carotenoid ornaments reliably reflect quality (through testosterone: McGraw and Blount, 2009; Weaver et al., 2017), even though carotenoids are evidently not limiting (Hill, 2006, 2014; McGraw and Blount, 2009; Simons et al., 2014). Simons et al. (2015) have proposed mutations that would allow an organism to cheat with a dishonestly advantageous ornament that would cost the cheater less than the cost imposed by honesty. The absence of these mutations in natural populations — and the prevalence of honest carotenoid ornaments - is difficult to explain.

Additionally, the well-studied zebra finches use song as an honest signal of quality, as song reliably indicates testosterone levels in development (Ritschard et al., 2011; Fedurek et al., 2016), even though: 1) song is metabolically cheap (Ritschard et al., 2010; Zollinger et al., 2011); 2) stressed birds incur song deficits even after a song allotment that is adequate for exact copying in other birds (Brumm et al., 2009); and 3) some nutritionally-stressed populations of wild zebra finches have more complex songs than populations with greater food availability (Zann and Cash, 2008). All of these findings indicate that zebra finches could have evolved the ability to learn complex song irrespective of nutritional stress. The maintenance of zebra finch song as a reliable indicator of quality is, therefore, perplexing. 
2) Why are sexually-selected characteristics associated with a higher susceptibility to parasites, even though the susceptibility is not well-explained in terms of an energetic tradeoff?

In a meta-analysis, Roberts et al. (2004) found no effect of androgens upon direct measures of immunity, but they did find androgens to increase ectoparasite abundance in several studies. In a larger, more recent meta-analysis, Habig and Archie (2015) replicated the finding that dominant males are consistently more susceptible to a breadth of parasites, but found that result "puzzling," since they could find no significant differences between the immune responses of dominant and subordinate males. They suggested that dominant males may suppress antibody production in response to antigens, which is an aspect of the less energetically costly Th-2 mediated immunity contrary to how organisms reducing immunity to save energy would be predicted to operate (Lee, K., 2006).

Consequently, Habig and Archie (2015) concluded that their results do not support the hypothesis that dominant organisms sacrifice immune function for greater reproductive effort. Relatedly, Kankova et al. (2014) found that when Japanese quail offspring were subjected to moderate caloric restriction during development, the offspring with high egg testosterone content retained their growth advantage and did not suffer an immunity disadvantage. They concluded that their results contradict a hypothesized tradeoff between growth and immunity. Interestingly, subordinate organisms do not exhibit stronger immunity responses or even greater resistance to infections in general, though they exhibit heightened antibody responses to antigens that are representative of the immune challenges that would occur in a natural environment (Cavigelli and Chaudhry, 2012).

\subsection{Lower-quality individuals incur a cost in obtaining reproductive success}

The first paradoxical finding — the honest signaling of quality despite an apparent opportunity to cheat—represents a cost against reproductive success that is incurred by low-quality individuals. When quality is signaled honestly, the favorability of the signal is determined by the signaler's quality, which means low-quality organisms signal less favorably. By signaling less favorably, low-quality organisms lose fitness, since mates, as well as food and territory, are more likely to go to organisms with better signals (Folstad and Karter, 1992; Hauser, 1997; Groothuis et al., 2005).

\subsection{Individuals that are not identified as lower-quality incur a burden in surviving parasites and/or predators}

The second paradoxical finding — susceptibility to parasites incurred by higher-quality organisms — represents a burden in surviving natural enemies that is incurred more by individuals that are not identified as low-quality. This 
explanation for the susceptibility to parasites of higher-quality organisms is supported by patterns of maternal investment of carotenoids, which help fight infections, in offspring. Findings of an inverse relationship between parental quality and maternal investment of carotenoids (Saino et al., 2002; Navara et al., 2006; Safran et al., 2008; Bolund et al., 2009) are contrary to theory (Safran et al., 2008) and contrary in a manner consistent with the pattern in section 1, since offspring quality correlates with parental quality.

\subsection{Males incur a burden in surviving parasites and/or predators}

In numerous species, males are more susceptible to infection than females, which is attributable to both physiological and genetic differences that cause them to be more susceptible to infection even if the settings are controlled (Klein, 2000). Male parasite susceptibility owes to their suppression of Th-2 (humoral) immunity (Zuk, 1990), which is contrary to how organisms reducing immunity to save energy would be expected to act (Lee, K., 2006) but is consistent with the pattern in section 1 .

5.6 Females incur a cost in obtaining reproductive success

In many species, males exhibit more prominent and conspicuous signals of quality than females (Andersson, 1994). This is explained by current sexual selection theory (Bateman, 1948; Trivers, 1972) and is also consistent with the pattern in section 1.

5.7 In response to indications that conditions are challenging, individuals improve in surviving parasites and/or predators

Exposure to higher levels of infection is indicative of more challenging conditions. Higher doses of infection have been found to increase antibody production in numerous species, including guinea pigs, sheep, and mice (Salvin, 1958; Wortis et al., 1966; Parish, 1972; Lagrange et al., 1974; Hernandez-Pando et al., 1997).

\subsection{In response to indications that conditions are challenging, individuals improve in reproductive success}

In addition to finding that infections sometimes diminish signals, biologists have documented that infections sometimes augment signals (reviewed in Duffield et al., 2017). The former findings are consistent with the idea that certain signals are honest indicators of quality (see section 5.1); the latter findings are typically explained in terms of the terminal investment hypothesis (Williams, 1966; Clutton-Brock, 1984). Evidence in favor of the terminal investment 
hypothesis is equivocal according to Duffield et al. (2017), who observed that organisms exposed to low levels of infection tend to reduce reproductive investment, whereas organisms exposed to higher levels tend to increase reproductive investment. Insofar as higher doses of infection indicate challenging conditions more than low quality, the improvements in signaling that occur in response to higher doses of infection (see Duffield et al., 2017) are consistent with the pattern in section 1 .

\section{Reproductive suppression}

\subsection{Background}

Reproductive suppression (which has also been called "socially induced suppression," "physiological suppression," and "social contraception") occurs when subordinate organisms exhibit a diminished physiological capacity for, and/or interest in, reproduction. This has been documented in mammals, birds, fish, and invertebrates (Saltzman et al., 2009) and sometimes occurs even though subordinates show comparable body condition to dominants and overlap dominants substantially in age (Saltzman et al., 2009; Clutton-Brock et al., 2010; Harrison et al., 2013). In some species, a group's subordinates are completely incapable of reproduction; however, their fertility and libido quickly return if the dominant group members depart the group (Sapolsky, 2001).

\subsection{Paradox}

Despite well-established theory about how organisms in a group are expected to divide reproduction (Vehrencamp, 1983), multiple large reviews have determined that theory is not matched well by experimental and observational results (Field, J. et al., 1998; Nonacs and Hager, 2011). Indeed, a review by Nonacs and Hager (2011) reported (pg., 295) that "some individuals appear to behave suboptimally and lose fitness by either joining disadvantageous groups or not leaving them." Subordinates' reproductive suppression is considered an evolutionary paradox (Johnstone, 2000; Saltzman et al., 2009; Clutton-Brock et al., 2010).

\subsection{Lower-quality individuals incur a cost in obtaining reproductive success}

Insofar as a subordinate status indicates lower quality (as Georgiev et al., 2015 suggested), a subordinate's inhibition of reproduction and associated fitness loss is consistent with the pattern outlined in section 1.

6.4 Individuals that are not identified as lower-quality incur a burden in surviving parasites and/or predators 
Higher quality can be indicated by a dominant status (Georgiev et al., 2015). Dominant organisms consistently have higher parasite loads across a variety of taxa (Habig and Archie, 2015).

\subsection{Males incur a burden in surviving parasites and/or predators}

Males in numerous species are more susceptible to infection than females, which is attributable to both physiological and genetic differences that cause them to be more susceptible to infection even if the settings are controlled (Klein, 2000).

6.6 Females incur a cost in obtaining reproductive success

In groups characterized by reproductive suppression, biologists have found support for a hypothesis that reproductive suppression is stronger in females (Hauber and Lacey, 2005; Rubenstein and Lovette, 2009; Young and Bennett, 2013; Yamamoto et al., 2014; Chak et al., 2015).

6.7 In response to indications that conditions are challenging, individuals improve in surviving parasites and/or predators

Higher doses of infection are consistent with more challenging conditions. Higher doses of infection also increase antibody production in numerous species, including guinea pigs, sheep, and mice (Salvin, 1958; Wortis et al., 1966; Parish, 1972; Lagrange et al., 1974; Hernandez-Pando et al., 1997).

6.8 In response to indications that conditions are challenging, individuals improve in reproductive success

Outside of the reproductive suppression literature, the hormesis literature (Calabrese, E. and Baldwin, 2001; Calabrese, E., 2005; Calabrese, E. and Blain, 2011; Calabrese, E., 2013a; Calabrese, E., 2013b) and the reproductive compensation literature (Gowaty et al., 2007; Gowaty, 2008; Ratikainen and Kokko, 2010) both document that certain stressors can increase an organism's fecundity, though too-high dosages of the same stressors can reduce it. In particular, the hormesis literature documents that physical stressors such as insecticide, ethanol, and radiation can increase an organism's reproductive success (e.g., Ayyanath et al., 2013, 2014; Shephard, A. et al., 2018) and strengthen antibody responses (Calabrese, E., 2005), in conjunction, apparently, with overall fitness gains. Hormesis is further discussed in section 8 .

\section{Stress-induced anthocyanin production}

\subsection{Background}


Plants of many species respond to a wide variety of stressors (strong light, UV-B radiation, temperature extremes, drought, nutrient deficiencies, bacterial and fungal infections, wounding, herbivory, herbicides, and various pollutants; Gould et al., 2009) by 1) producing anthocyanins, which imposes a photosynthetic cost (Manetas, 2006; Karageorgou et al., 2008; Gould et al., 2009), and 2) increasing production of defensive compounds against parasites. The phenomenon is biochemically wellexplained. Defensive compounds against parasites (e.g., phenols, tannins; Schaefer and Rolshausen, 2006) are produced in a common biosynthetic pathway with anthocyanins, causing plants to produce both defensive compounds and anthocyanins in response to stressors.

\subsection{Paradox}

An increase in defense compounds in response to stress should be possible without suffering a photosynthetic cost. That is, mutations could have decoupled the production of defensive compounds from the photosynthetic cost. Consequently, the production of anthocyanins during stress is an evolutionary paradox (Manetas, 2006; Gould et al., 2009; Cooney, L. et al., 2012; Kovinich et al., 2014; Menzies et al., 2016). Manetas (2006, pg. 173) echoed Haberlandt (1914) who wrote that "the general physiological and ecological significance for the presence of anthocyanins in vegetative organs is still very obscure." The paradox is reinforced by an apparent evolutionary convergence. Plants of the order Caryophyllales do not produce anthocyanins. However, they produce betalains, which are produced by very different biosynthetic pathways, but which are considered to be a substitute for anthocyanins. Like anthocyanins, betalains evidently: 1) are produced in response to many sources of stress (e.g., UV light, drought stress, salt stress, cold temperatures, and pathogens); 2) reduce the light available for photosynthesis; and 3) participate in defense against herbivory (Steyn et al., 2002; Berardi et al., 2013; Hatlestad and Lloyd, 2015; Jain and Gould, 2015; Miguel, 2018; Polturak and Aharoni, 2018).

\subsection{Lower-quality individuals incur a cost in obtaining reproductive success}

Compared to animal populations, much is unknown about dynamics in plant populations. This creates obstacles for observers in determining a plant's quality. For example, unlike animals, it is difficult to ascertain whether a plant is, for example, subjected to bullying and social defeat stress; well-nurtured by parents; well-received by potential mates; or dominant or subordinate. All of these occurrences have been discussed in this manuscript as potential indicators of quality. 
Insofar as the stressors inducing anthocyanin production occur in contexts that indicate low quality (see section 2), the anthocyanin production is consistent with the pattern in section 1: The photosynthetic cost associated with anthocyanin production reduces reproductive success (Obeso, 2002).

\subsection{Individuals that are not identified as lower-quality incur a burden in surviving parasites and/or predators}

Insofar as stressors that induce anthocyanin production occur in contexts that indicate lower quality (see section 2), the lesser production of defensive compounds by unstressed plants is consistent with this pattern.

\subsection{Males incur a burden in surviving parasites and/or predators}

In dioecious plant species, male plants exhibit significantly lower concentrations of defense compounds and are consistently subjected to more herbivore damage, than female plants, which may cause the female-biased sex ratios in natural populations (Agren, 1999; Cornelissen and Stilling, 2005). Moreover, the male stamen tends to have lower concentrations of defense compounds than female reproductive parts of the same plant (Sadikoglu and Cevahir, 2004; Serrano-Diaz et al., 2012; Davis et al., 2014). Sex differences involving parts of the same plant are particularly difficult to reconcile with tradeoff hypotheses. Findings suggest that monoecious plants invest more in defense compounds for female reproductive parts (Sadikoglu and Cevahir, 2004; Serrano-Diaz et al., 2012), even though this greater investment is contrary to theory holding that the greater investment should be in the rarer sex (Fisher, 1930) and contrary in a manner consistent with the pattern outlined in section 1.

\subsection{Females incur a cost in obtaining reproductive success}

Andromonoecious plants with higher numbers of staminate (male) flowers produce more seeds (Vallejo-Marin and Rausher, 2007). Additionally, pollen from male flowers produce more seeds than pollen from perfect flowers (Zhang, T. and Tan, 2009).

7.7 In response to indications that conditions are challenging, individuals improve in surviving parasites and/or predators

A plant actively recruits plant growth promoting bacteria and fungi when it is subjected to stressors, such as parasites or drought (Yang, J., et al., 2011; Berendsen et al., 2012; Lee, B., et al., 2012; Kim et al., 2016; Kong et al., 2016; Naylor and Coleman-Derr, 2017). These plant growth promoters increase a plant's photosynthetic capacity and its production of 
leaf phenols (Mucciarelli et al., 2003; Barka et al., 2006; Singh et al., 2015). Insofar as the stressors that lead to a plant to recruit these promoters occur in contexts indicative of challenging conditions (see section 2), the consequential production of leaf phenols is consistent with the pattern in section 1.

7.8 In response to indications that conditions are challenging, individuals improve in reproductive success

Insofar as the stressors that lead a plant to recruit plant growth promoting bacteria and fungi (Yang, J., et al., 2011; Berendsen et al., 2012; Lee, B., et al., 2012; Kim et al., 2016; Kong et al., 2016; Naylor and Coleman-Derr, 2017) occur in contexts indicative of challenging conditions (see section 2), the consequential increase in photosynthetic capacity (Mucciarelli et al., 2003; Barka et al., 2006; Singh et al., 2015) is consistent with the pattern in section 1.

\section{Hormesis}

\subsection{Background}

Hormesis (Calabrese, E. and Baldwin, 2001; Calabrese, E. and Blain, 2011; Calabrese, E., 2013a; Calabrese, E., 2013b) is sometimes defined rather generally as a biphasic response to a stimulant. However, the controversy about hormesis (Calabrese, E. and Baldwin, 2000; Forbes, 2000; Thayer et al., 2005; Cook and Calabrese, 2006; Mushak, 2009; Jager et al., 2013; LeBourg and Rattan, 2014; McClure et al., 2014) and the chief significance of hormesis to the current paper, owes to a prevalence of studies that have suggested (or concluded after experimentation) that stressors can cause the fitness of stressed organisms to be higher than controls. Numerous stressors (e.g., ethanol, radiation, insecticide, herbicide, caloric restriction, and temperature stress) have been cited (Mattson, 2008a; Rattan, 2008; Costantini et al., 2010; Rattan and Demirovic, 2010; Haddi et al., 2016; Vargas-Hernandez et al., 2017) for apparently increasing fitness in a wide variety of taxa (e.g., plants, insects, invertebrates, vertebrates, humans), with the commonality being that the response is biphasic so that low doses of the stressor cause increases in fitness compared to controls and high doses of the stressor cause decreases.

\subsection{Paradox}

Many of the findings cited in section 8.1 were classified under the umbrella "paradoxical effects" before the term "hormesis" became commonly used (Calabrese, E., 2010). The "confusion and controversy" (Jager et al., 2013, pg., 263) about hormesis arises because, as McClure et al. (2014, pg., 2225) wrote, "Studies identifying beneficial influences of stress on fitness would challenge our understanding of evolution because it would imply that life histories are generally suboptimal." The most popular explanation among skeptics is that while one or more life history 
parameters may gain in response to stress, this occurs at the expense of one or more life history parameters and, therefore, does not increase Darwinian fitness. However, suggestions that stress-induced increases in reproduction come at the expense of longevity or immunity (McClure et al., 2014) are discredited by reports that both reproduction and longevity can increase in response to stress (Costantini, 2014, pgs., 26-27), as well as both reproduction and immunity (Calabrese, E., 2005; Rattan, 2008; Costantini et al., 2010; Yang, G. et al., 2016; Cui et al., 2017). Most saliently, physicians encourage physical exercise, fruits, and vegetables because they improve longevity, immunity, and overall health (Lampe, 1999; Gleeson, 2007; Rattan, 2008; Leitzmann, 2016). Physical exercise is a stressor and fruits and vegetables are thought to exert much of their favorable influences by invoking stress response pathways (Mattson, 2008a; Mattson, 2008b; Rattan, 2008; Calabrese, V. et al., 2012).

\subsection{Hormesis is associated with improvements in both reproductive success and surviving parasites and/or} predators in response to challenging conditions

The findings in sections 3.7, 5.8, and 6.8 can all be considered examples of hormesis because they are biphasic responses to stress. While many kinds of physical stressors have been found to increase fitness, it is notable that, to my knowledge, psychological stressors ${ }^{4}$ such as bullying and rejection have not been found to result in hormetic fitness gains (see, for example, Van der Vegt et al., 2009), even though psychological stressors can have physiological ramifications (Sapolsky, 1998). These sorts of psychological stressors are the kinds of stressors that are most often indicative of lower quality (see section 2).

In another example of hormesis, many authors have reported increases in a plant's reproductive output in response to grazing by herbivores or clipping by humans (Belsky, 1986; Paige and Whitham, 1987; Paige, 1999; Agrawal, 2000). This result is called overcompensation and is considered a paradox (Belsky et al., 1993; Lennartsson et al., 1997; Juenger and Bergelson, 2000; Banta et al., 2010). A particular peculiarity is the recent finding that, in response to damage, plants can both augment chemical defenses and produce more seeds, which contradicts theory that predicts a tradeoff between resistance and fitness compensation (Mesa et al., 2017). Overcompensation reportedly occurs in a biphasic manner by

\footnotetext{
${ }^{4}$ There are some difficulties in assessing whether psychological stressors such as bullying and rejection have a favorable effect on fitness, since there is often no scholarly effort to distinguish between these stressors and other psychological stressors that are more suggestive of challenging conditions, such as how often a child was left home alone and how often a child's basic needs were not accommodated.
} 
which low levels of herbivory cause productivity increases, while extreme herbivory reduces herbivory (Dyer et al., 1993). Therefore, it can be categorized as another example of hormesis.

\section{Bandwagoning can explain these six patterns}

Sections 3-8 consistently reveal six findings:

1) Lower-quality individuals incur a cost in obtaining reproductive success.

2) Individuals that are not identified as lower-quality incur a burden in surviving parasites and/or predators.

3) Males incur a burden in surviving parasites and/or predators.

4) Females incur a cost in obtaining reproductive success.

5) In response to indications that conditions are challenging, individuals improve in surviving parasites and/or predators.

6) In response to indications that conditions are challenging, individuals improve in reproductive success.

The reviewed literatures have stubbornly cascaded into these six patterns, even though, for each literature, some or all of these findings do not make sense when viewed through the lens of prevailing theory; therefore, they are considered paradoxes by biologists specializing in that literature.

Here, I introduce a specific form of genetic bandwagoning and explain how these six findings are consistent with predictions that would be made about this specific form of bandwagoning. In Solon's (2019) model and examples, the two steps of bandwagoning occur sequentially: First, the variant evaluates its holder's quality; second, the variant induces a low-quality holder to relinquish resources. Let us call sequential bandwagoning resonation ${ }^{5}$ to distinguish it from the form of bandwagoning called reservation, which is introduced below and enables the two steps of bandwagoning — the evaluation and the relinquishment— to occur simultaneously.

\footnotetext{
${ }^{5}$ We call sequential bandwagoning "resonation" because the effect of the relinquishment of resources upon a holder's lineage fitness resonates with what the evaluation suggested about the holder's lineage fitness outlook prior to the relinquishment: First, a holder is identified as having a low lineage fitness outlook (which is suggested by the holder's low quality) and then this outlook is lowered further.
} 
While bandwagoning can be done with resonation alone (see the examples in Solon, 2019), I focus below upon a form of bandwagoning that incorporates both resonation and reservation and that varies reservation by the conditions, sex of the holder, and indications about the holder's quality. It is this form that enables predictions (see section 9.8) that correspond with the six findings listed above.

\subsection{The purpose of reservation}

The best way to understand reservation is probably to think of the Red Queen depiction (Van Valen, 1973; Hartung, 1981; Ridley, 1993; Liow et al., 2011; Brockhurst et al., 2014) of how a population and its natural enemies coevolve: A population must evolve just to survive. Consider a focus population that has a natural enemy population, which may be predators or parasites. Suppose that in generation to, numerous organisms in the focus population can survive to reproductive age with little difficulty; however, in generation $t_{l}$, few (if any) of their offspring are able to survive. This may be because there were predators or parasites well-adapted against the focus population in $t_{0}$ but they gained frequency from $t_{0}$ to $t_{1}$, so organisms in generation $t_{l}$ are more exposed to well-adapted natural enemies. Additionally, it may be because predators or parasites nearly well-adapted to the focus population in $t_{0}$ have evolved from $t_{0}$ to $t_{1}$ to become better-adapted to the focus population. (Some combination of these two reasons is probable.)

Either way, it would be advantageous for a bandwagoning variant held by organisms in the focus population to identify in generation $t_{0}$ which of its holders has genes suited for surviving any well-adapted or nearly well-adapted natural enemies and which do not. This would enable the variant to induce its holder to perish in $t_{0}$ if it is not well-adapted, which would make more resources available to the better-adapted holders; consequently, the better-adapted holders in generation $t_{0}$ would produce more offspring than otherwise. This would improve the bandwagoning variant's chances of being held by at least one organism in generation $t_{l}$ that can survive: The betteradapted holders in $t_{0}$ are, being better-adapted, perhaps only a few mutations away from survival in generation $t_{l}-$ fewer than the other individuals. The more offspring these holders can produce, the more likely it is that at least one has the germline mutations allowing it to survive in generation $t_{l}$. The variant may, therefore, gain fixation, as many individuals are killed by natural enemies in $t_{1}$.

However, in this scenario, it is difficult to identify the better-adapted holders in $t_{0}$ because few have difficulty surviving: Any natural enemies well-adapted to the focus population are at low frequency in $t_{0}$. What a bandwagoning variant can do is induce its holders in $t_{0}$ to reserve from (i.e., withhold) some of their ability to 
survive the natural enemy, whether the natural enemy is a predator or a parasite. To reserve against a predator, the variant can induce its holders to, for example, exhibit bright colors; move around conspicuously; or don weighty ornaments. To reserve against a parasite, the variant can, for example, induce its holders to underproduce antibodies. By doing reservation, a holder becomes exposed to more predators and/or parasites and also becomes more susceptible to wounding, infection, or death from the predators and/or parasites to which it is exposed. This way, if there are natural enemies nearly well-adapted to an individual or well-adapted but at low frequency, it is more likely that the individual is killed as a consequence of undertaking reservation. More offspring are then produced by better-adapted holders.

Natural selection would shape the degree and character of reservation so that if a holder is genetically welladapted, it can survive in spite of reservation and if it is not, it becomes sick, wounded, or killed. This very sickness, wounding, or death both identifies the holder as poorly-adapted and also serves to cause the holder to be unable to use at least some of the resources for reproduction that it could have used. Consequently, reservation enables both steps of genetic bandwagoning to be accomplished simultaneously.

A bandwagoning variant can evolve to follow reservation with resonation. For example, if a holder undertakes reservation and subsequently becomes infected or wounded, that holder is consequently evaluated to be low-quality and also, as a consequence of the infection or wounding, becomes unable to use some of the resources it might have. However, that holder may remain alive and capable of using some resources. Since the holder's quality has been evaluated to be low, a bandwagoning variant may induce the holder to forego resources (which would be an example of resonation). In resonation, the holder would relinquish more resources in addition to those lost as a direct result of the infection or wounding.

Reservation can theoretically evolve to occur in multiple ways by the same organism simultaneously. For example, an organism might undertake reservation from ability to avoid predators by exhibiting a bright or weighty ornament and simultaneously undertake reservation from ability to resist parasites by reducing its quantities of antibodies. The bandwagoning variant would evolve to allow an individual to reproduce only if it were able to survive the effects of both ways of reservation.

Reservation is intended to be conditional. Indeed, it would not be practiced to the same degree at all times by all holders. If it were, holders would reserve not just when better-adapted natural enemies are at low frequency, 
but also when they are at high frequency. If that were to occur, there would be few (if any) holders remaining alive to utilize the resources foregone by individuals killed by the natural enemies. Sections 9.3 to 9.6 discuss how the degree of reservation practiced may vary based upon, respectively, the conditions; the holder's quality; and the sex of the holder.

\subsection{Reservation relies upon a premise of differential costliness}

Reservation relies upon the premise that an organism's adaptedness against a natural enemy population can be demonstrated by imposing a burden that is costlier to ill-adapted organisms than to well-adapted organisms. Reservation works because ill-adapted organisms that reserve suffer from infection, wounding or death, which helps identify them in comparison to well-adapted organisms that reserve and do not suffer similarly.

In this reliance upon a criterion of differential costliness, the concept of reservation is similar to the handicap principle (Zahavi, 1975; Grafen, 1990). Zahavi (1975) introduced the handicap principle, but it was unpopular among evolutionary biologists for a decade and a half. Then Grafen (1990) emphasized a criterion of differential costliness, holding that in order for a signal to reliably indicate quality to organisms with conflicting interests, it has to be costlier ${ }^{6}$ to maintain for lower-quality organisms. Additionally, Grafen (1990) included a model showing how this criterion might be satisfied. His work instantly transformed the biological community's view of the handicap principle (per Grose, 2011) some fifteen years after Zahavi (1975). Though the concept of reservation is distinct from Grafen's version of the handicap principle, they both rely upon this criterion of differential costliness; therefore, the biological community's acceptance of the idea that this criterion can be satisfied confers credibility to the notion that bandwagoning in the form of reservation can evolve. (See also section 9.7 for similarities and differences between the concept of reservation and the handicap principle.)

\subsection{When conditions are more challenging, a bandwagoning variant does less reservation and less resonation}

The severity of conditions can vary by place and time. One cause of changing conditions has been mentioned above (section 9.1): the spread of well-adapted natural enemies. However, there are other factors that

\footnotetext{
${ }^{6}$ Subsequently, Getty $(1998,2006)$ demonstrated that signaling can reliably reflect quality even if the costs of signaling are not higher for lower-quality organisms, provided that higher-quality organisms receive a benefit from the signaling that sufficiently exceeds the benefit that lower-quality organisms would receive. However, reservation depends upon a differential costliness criterion because it is used by organisms to identify their own quality.
} 
can make survival and reproduction easier or more challenging for the average individual in a particular location at a particular time. These include the quantity of suitable prey and territory and the environmental conditions (e.g., weather).

If conditions are more challenging, a bandwagoning variant should induce less reservation than it otherwise would. This is true whether or not the main source of the challenging conditions is the natural enemy against which the reserved abilities are used. That is, whether the challenging conditions are because predators are prevalent or because virulent parasites are prevalent, an organism should both undertake less reservation from ability used to avoid predators than otherwise and less reservation from ability used to resist parasites than otherwise. This is because if conditions are challenging, the quantity of bandwagoning variant holders that survive to any particular age figures to be lower than usual. Since the pool of holders is smaller, the number of holders that can survive reservation of any particular degree is also smaller. If no holders can survive the reservation, there are no holders remaining to use the resources foregone by individuals that are killed. Therefore, holders would be expected to undertake less reservation when conditions are challenging.

Additionally, if other indicators of quality are constant, the more challenging the conditions faced by an organism, the higher the quality that organism is indicated to be. For example, whether an organism has experienced a bout with hunger or eaten amply, that organism's quality is indicated to be higher-quality if a drought has occurred than if food in the area is plentiful. Since an organism's quality is indicated to be higher if conditions are more challenging (when other quality indicators are constant), a bandwagoning variant is also less likely to induce that organism to relinquish resources through resonation under the same circumstances.

Resonation and reservation both temporarily reduce the quantity (but increase the mean quality) of bandwagoning variant holders. As discussed above, they both occur more when conditions are easy and there are likely numerous surviving holders and less when conditions are severe and there are likely far fewer surviving holders. This smooths the variance across time of the offspring produced by holders, in accordance with theory that holds that long-term natural selection favors a genotype with a lower net variance of offspring produced across time (Schreiber, 2015). 
As discussed in section 9.3, reservation is expected to be dialed back when conditions become more challenging. However, conditions can change suddenly. For example, well-adapted predators or parasites can rapidly proliferate via the spread of a mutation that is advantageous to them. Therefore, a bandwagoning variant that induces all of its holders to engage in reservation at the same time and to the same degree runs the risk of leading to the death of all of its holders if the predator or parasite threat to the population suddenly intensifies. If this were to occur, there would be no bandwagoning variant holders left to utilize the resources forfeited by the perished organisms. Consequently, a bandwagoning variant would likely evolve to hedge against the potential that conditions rapidly intensify by varying the timing and/or degree of the reservation it induces its holders to undertake. In doing so, a bandwagoning variant reduces the correlation of offspring produced between its holders during the same generation, in accordance with theory that holds that long-term natural selection favors a genotype with a lower correlation of offspring produced between two-randomly selected holders from the same generation (Schreiber, 2015).

\subsection{Varying reservation based upon quality indications so far}

One way to vary reservation is based on the degree to which the holder's quality has been indicated to be low so far, so that holders evaluated as low-quality so far reserve less (or not at all) than holders not (yet) evaluated as lowquality. Indeed, Solon (2019, section 5) discussed how evaluating a holder's quality is a continuous process: If, so far, a holder's quality is evaluated to be low but this evaluation of its quality and lineage fitness outlook is more likely to change, then the variant is more likely to allow the holder to remain alive and induce only a partial relinquishment of the holder's resources; if change is unlikely, a variant is more likely to induce suicide.

One key way a holder's quality and outlook for lineage fitness might change is if the conditions turn more severe, which would elevate these evaluations for any surviving organisms. As long as conditions remain modest, a holder evaluated to be low-quality will likely be induced to engage in resonation even if it survives, so reservation is unnecessary. Alternatively, if conditions become more severe, reservation is dialed down (section 9.3).

Consequently, there is little purpose to reservation by individuals evaluated to be low-quality so far. A bandwagoning variant would, therefore, likely evolve to induce less reservation (or none at all) by holders that have so far been evaluated to be low-quality.

9.6 Varying reservation based upon sex 
In addition to inducing less reservation by holders identified so far as low-quality, another means of varying reservation is to vary it by the sex of the holder. A bandwagoning variant might induce less reservation by holders of the sex that undertakes more reproductive investment (typically, females). This pattern of variation would cooccur with variation by quality, such that males not already identified as low quality might reserve the most and females already identified as low quality might reserve the least. Doing so would further reduce the correlation of offspring produced between its holders during the same generation, in line with theory (Schreiber, 2015).

A bandwagoning variant would evolve to induce less reservation by females than males rather than the other way around because the purpose of varying reservation from holder to holder is to hedge against the possibility of a sudden proliferation of well-adapted predators or parasites. A proliferation of well-adapted predators and/or parasites can suddenly kill many organisms, which would tend to drive the population far below its carrying capacity, leaving a surplus of food and territory resources available due to the large quantity of perished organisms.

If the population is below carrying capacity, it is beneficial to the bandwagoning variant for numerous females to be alive, since fecundity is typically limited by this sex (Lively, 2011). (This is a departure from more ordinary circumstances, in which food or territory resources might not be sufficient to support high fecundity.) Therefore, a bandwagoning variant would vary the reservation it induces in a manner that spares the sex engaging in greater reproductive investment if conditions turn severe: Under normal conditions, it would induce less reservation by females than by males to ensure that females, in particular, are spared if conditions suddenly intensify.

If males reserve more than females, they are more susceptible to predators and parasites, so fewer males would reach reproductive age. Presuming no difference in mean quality between male and female holders at birth, the male holders that survive would have higher mean quality than female survivors because the male holders had to survive more reservation, leading more males to die if they are not high-quality. Consequently, resonation would occur less in males than in females.

Findings of higher male fecundity and greater male susceptibility to natural enemies are also compatible with prevailing theory, which holds that 1) males are more sexually indiscriminate due to their lower reproductive costs (Bateman, 1948; Trivers, 1972) and that male susceptibility to natural enemies may result 2) from tradeoffs associated with higher investment in male-male competition (Bateman, 1948; Trivers, 1972) and/or 3) from handicaps they incur against natural enemies in order to impress females (Zahavi, 1975; Grafen, 1990). The first two of these 
assumptions have been challenged recently on theoretical and empirical grounds (Snyder and Gowaty, 2007; Gowaty et al., 2012; Tang-Martinez, 2016), though other authors have argued in their favor (Janicke et al., 2016). The third, the handicap principle, is discussed in section 9.7 in terms of reservation. Therefore, it is worth noting that bandwagoning theory is also compatible with sex differences in fecundity and susceptibility to natural enemies.

\subsection{Similarities and differences between the concept of reservation and the handicap principle}

The concept of reservation is similar to the handicap principle (Zahavi, 1975; Grafen, 1990) in the following respects. They both hold that there has been natural selection of a variant:

1) that imposes a burden upon its holder

2) for the purpose of helping to identify that holder's quality

3) and that holder quality can be identified because the burden is costlier to lesser-adapted holders (which is discussed in section 9.2)

4) and that the burden is incurred conditionally (see section 9.1),

5) so that organisms that are so far identified as low quality incur less of a burden or none at all (see section 9.5) and

6) males incur more of a burden than females (see section 9.6).

A key difference is that according to the handicap principle, this burden is incurred for the purpose of helping to identify the holder's quality to other organisms, particularly potential mates (Zahavi, 1975), but also other conspecifics and natural enemies (Zahavi and Zahavi, 1997); for reservation, this burden is incurred for the purpose of helping to identify the holder's quality to the bandwagoning variant that is responsible for the burden. This distinction allows bandwagoning theory to better account for some findings the handicap principle has been invoked to explain with limited success, such as burdens incurred in parasite resistance that are not directly verifiable by conspecifics. For this reason, sections 3 through 8 focus upon examples that involve burdens incurred against parasite resistance.

Another difference is that bandwagoning theory predicts that the burden incurred might vary not just by quality and by sex, but also by other characteristics, for example, birth order. Bandwagoning theory would predict that resonation would occur less by individuals that reserve more and survive, for the same reason males are predicted to 
resonate less (see section 9.6). For example, if individuals of a higher birth order reserve more than first-born individuals in a population, they would also be predicted to do less resonation.

\subsection{Predictions}

Here, I summarize the predictions that can be made regarding empirical findings if organisms combine resonation and reservation as described in this section:

1) resonation by organisms identified as low quality, which would lose reproductive opportunities and other resources.

2) reservation particularly by organisms not (yet) identified as low-quality, thereby increasing their exposure and susceptibility to predators and parasites.

3) more reservation by males than females.

4) more resonation by females than males.

5) less reservation in response to indications that conditions are more challenging.

6) less forgoing resources through resonation in response to indications that conditions are more challenging.

These six predictions correspond to the six findings identified in the paradoxical phenomena reviewed in sections 3 to 8.

\section{The literatures reviewed in sections 3 to 8 in terms of genetic bandwagoning}

\subsection{Depression}

The reduced libido, self-loathing, and self-neglect associated with depression occur in response to indications of low quality. These costs allow reproductive opportunities and other resources to be used by higher-quality individuals. Therefore, these responses are consistent with resonation.

Additionally, the enhanced physiological resistance against infection in depression is consistent with reservation by individuals that do not have depression — that is, reservation by individuals that are not identified as low-quality. This occurs when conditions are unchallenging in order to identify individuals that would not be able to survive a more challenging parasite threat. Those that would not survive likely would have descendants that would be killed when the parasite threat becomes more challenging; instead, when they undertake reservation, they 
perish or become sick and some or all of their resources go unused, which are then used by higher-quality individuals - that is, individuals that would be able to survive a more challenging threat.

As a hedge against the possibility that conditions suddenly intensify, females undergo less reservation. Since more males undertake reservation, more males typically perish. The surviving males have demonstrated, through their ability to survive in spite of reservation, that they are, on average, higher-quality than the surviving females; therefore, they are less likely to relinquish resources through resonation. Both the greater male reservation and the greater female resource forfeitures are consistent with higher rates of depression among females: The greater male reservation corresponds to the lesser infection resistance among non-depressives and the greater female resource forfeitures corresponds to the reproductively costly moods associated with depression.

Findings that physical exercise causes a decrease in depressive moods and an increase in infection resistance are consistent with less forfeitures of resources through resonation and downregulated reservation, both of which would be expected under more challenging conditions.

Evolutionary explanations that maintain that depression is solely prevent infection fare poorly in explaining why depression usually results not from a single stressful incidence but from prolonged (i.e., chronic) stress and that the likelihood of developing depression is higher if the person has a history of it (Ghaziuddin et al., 1990; Kendler et al., 2000; Solomon et al., 2000; Brilman and Ormel, 2001). Indeed, a history of stress that has not resulted in an infection would suggest that further stressful incidents are less likely to be caused by infection. However, in the context of genetic bandwagoning theory, a history of chronic stress is more indicative than a single instance of stress that the stress was due not to luck but to the person's genetic quality. Therefore, a bandwagoning variant would be more likely to induce its holder to completely forfeit its current resources and the resources it might subsequently obtain (i.e., via suicide) if the holder has had a history of chronic stress.

\subsection{Differential nurturing}

The differential nurturing is decided by the mother. However, the mother confers no resources to the offspring through nurturing. Therefore, biologists generally treat the level of nurturing as a signal, rather than a resource, and it is presumably a signal that the offspring could abide or not. Consequently, insofar as the results of low nurturing 
are consistent with bandwagoning, I consider the offspring to have undertaken resonation and reservation, not the mother.

In the bandwagoning interpretation, lower-quality offspring do resonation in the form of the costs associated with less nurturing, including less growth, lowered cognitive function, more depression, and higher mortality risk. The lower parasite resistance and predator vigilance by better-nurtured offspring constitute reservation by individuals not (yet) identified as low-quality.

Females are nurtured less, so they incur more reproductive costs associated with lower nurturing and they are also better able to avoid predators and resist parasites, as these capacities are also evidently enhanced by lower nurturing. The relatively lesser male capacities to avoid predators and resist parasites that follow from their having been nurtured more are consistent with more reservation by males. Since females reserve less, the average quality of the surviving female is, therefore, lower than the average male that survives reservation. Consequently, the average female would forego more resources through resonation, which is also consistent with lower nurturing to females, as lower nurturing causes reproductive costs.

Additionally, predator odor causes both increased vigilance to predators and enhanced nurturing, which is consistent with, respectively, less reservation and less forfeitures of resources through resonation under challenging conditions.

I argued in section 9.5 that organisms identified to be low-quality so far would do less reservation in case conditions suddenly turn severe. Findings suggesting that paternal absence and reduced maternal nurturing induce, in females, earlier and more indiscriminate sexual interest (Dickins and Rahman, 2012) are consistent with another phenotypic adjustment made by low-quality organisms in case conditions turn severe: Severe conditions (especially those caused by predators or parasites) would warrant earlier and more indiscriminate sex. Females that physically develop faster often do not attain higher reproductive success (Ellis, 2004), which is consistent with the suggestion that low-nurtured females typically do resonation, while also making phenotypic adjustments in case conditions turn severe. (The relationship between age of pubertal development and reproductive success is not a simple one from which to draw conclusions, due to the alteration of pubertal timing by numerous factors besides psychological stress.) 


\subsection{Honest signaling and the susceptibility to parasites associated with sexually-selected characteristics}

In the bandwagoning interpretation, the unfavorable signaling by low-quality individuals constitutes their relinquishment of resources through resonation. The lower parasite resistance and ability to evade predators of individuals with more favorable signals constitute reservation by individuals that have not (yet) been identified as low-quality.

The greater male susceptibility to infection is consistent with more reservation by males. The more prominent signaling of quality by males is consistent with more resonation by females and can also be consistent with more reservation by males in cases in which signals of quality cause their bearers to have vulnerabilities against predators.

The increased antibody production and enhanced signaling in response to higher levels of infection are consistent with downregulations of, respectively, reservation and resonation in response to more challenging conditions.

Duffield et al. (2017) observed that organisms exposed to low levels of infection tend to reduce reproductive investment, whereas organisms exposed to higher levels tend to increase reproductive investment. The former response is consistent with resonation (prediction 1; section 9.8); the latter is consistent with a downregulation of resonation (prediction 6; section 9.8). In terms of bandwagoning theory, exposure to low levels of infection may be more consistent with low genetic quality, to which a response of resonation would be predicted, whereas exposure to higher levels of infection may be more indicative of challenging conditions, to which a response of downregulating resonation would be predicted. This is explained as follows. A stressor, such as infection, is expected to result in a downregulation of reservation, whether that stressor is received more as an indicator of low quality (see prediction 2; section 9.8) or more challenging conditions (see prediction 5; section 9.8). With the downregulation of reservation occurring under either indication, the organism's susceptibility and likelihood of further exposure to infection are reduced. If the organism continues to be exposed to infection despite the downregulation of reservation, it is more suggestive of challenging conditions.

10.4 Reproductive suppression 
In the bandwagoning interpretation, the suppression of reproduction by subordinates constitutes resonation. The lower parasite resistance of dominants constitutes reservation.

The greater susceptibility of males to infection is consistent with more reservation by males. The stronger reproductive suppression in females is consistent with more forfeitures of resources through resonation by females.

The antibody production increases and fecundity increases that both occur in response to higher doses of infection are consistent with, respectively, less reservation and less forfeitures of resources through resonation under challenging conditions. The fecundity costs associated with the highest dosages of stressors are also consistent with bandwagoning theory: If the stressors are too challenging, their adverse impacts upon immunity and fecundity outweigh the favorable effects upon immunity and fecundity resulting from less reservation and less resonation.

In support for the notion that reproductive suppression is an example of resonation rather than an attempt to avoid bullying by dominants, levels of subordinate submissiveness and reproductive inhibition often vary within a group. Ovulatory subordinates are less submissive than anovulatory subordinates and individual differences in aggressiveness and submissiveness reliably predict subsequent social status, supporting the idea that a female's suppression of ovulation is determined primarily by that female's perception of herself as a subordinate, rather than her receipt of agonistic behaviors (Saltzman et al., 2009).

\subsection{Stress-induced anthocyanin production}

In the bandwagoning interpretation, the photosynthetic cost incurred by plants producing anthocyanins constitutes resonation. The lower resistance to infection of plants that do not produce anthocyanins constitutes reservation.

The lesser defensive compounds exhibited by male plants and male reproductive parts are consistent with more reservation by males. The lower quantities of seeds and pollen produced by plants with lower numbers of male flowers are consistent with more resonation by females.

The greater photosynthetic capacity and production of leaf phenols under circumstances of parasites or drought are consistent with downregulations of, respectively, resonation and reservation in response to more challenging conditions. 
Plants that produce anthocyanins forego the resource of sunlight. Sunlight is different from other resources (e.g., food, territory, reproductive opportunities) because when it is foregone by low-quality organisms, it is not as readily used by nearby organisms. If the stress-induced production of anthocyanins is an example of bandwagoning, I predict that other resources besides light are limiting to photosynthesis and that, in conjunction with incurring the photosynthetic cost, the stressed plant releases these limiting resources that can be used by neighboring plants. Consistent with this prediction, plants release numerous kinds of resources to neighboring plants (Teste et al., 2009; Simard et al., 2012; Gorzelak et al., 2015) and stress is one factor that causes a plant to release resources (Song et al., 2015). So why incur the photosynthetic cost? Indeed, the resonation by a stressed plant could be conducted with solely the release of resources, without incurring the photosynthetic cost. The leaf reddening itself in response to stress may be explained by the defense indication hypothesis (Schaefer and Rolshausen, 2006), the photoprotection hypothesis (Gould et al., 2018), and/or another hypothesis of adaptive function (Strauss and Whittall, 2006; Gould et al., 2009). However, bandwagoning theory can offer an explanation for why the leaf reddening is done by stressed plants and not by unstressed plants: Stressed plants have less to lose from incurring a photosynthetic cost because they, in resonation, are sending to nearby plants resources that limit photosynthesis.

\subsection{Hormesis}

In the bandwagoning interpretation, the improved reproduction and resistance to infection occurring in response to stress constitutes a downregulation of resonation and reservation in response to challenging conditions.

In some literatures, a stressor up to a particular threshold is found to offer a benefit to reproductive success and/or immunity, while a stressor of higher magnitude has a detrimental impact. This is compatible with bandwagoning theory. If the stressor is severe enough, the positive effect of a downregulation of resonation and reservation upon, respectively, reproductive success and immunity may be exceeded by the negative effect of the stressor itself. An inverted-U-shaped relationship between stressor intensity and fitness is, therefore, consistent with bandwagoning theory.

Males often experience greater benefits from hormesis than females (LeBourg et al., 2000; Sorensen et al., 2007; Costantini et al., 2010; LeBourg and Rattan, 2014). This finding is also potentially explained by bandwagoning theory. Males are expected to engage in more reservation than females (see prediction 3; section 9.8). Therefore, stress that suggests challenging conditions causes all individuals were to completely refrain from reservation, males would 
have a greater gain ${ }^{7}$ in ability against natural enemies. The greater hormetic benefits to males have occurred mostly in the form of longevity. An explanation offered by bandwagoning theory would be that the greater longevity gains for males come through improvements in resisting natural enemies, particularly parasites. This remains to be assessed.

\section{Discussion}

I argued that numerous empirical phenomena that currently await evolutionary explanation can be explained by their accordance to six predictions about a variant that hedges reservation based on conditions, sex, and indications of quality already received. However, genetic bandwagoning does not necessarily involve reservation. Indeed, Solon (2019) offered a model and examples of genetic bandwagoning that only involve resonation.

The empirical phenomena reviewed mostly involved increases in exposure, and susceptibility, to parasites that were explained as examples of reservation. Increases in exposure, and susceptibility, to predators can also be explained in terms of reservation but I did not focus upon such phenomena, since they are not considered paradoxical: They can also be explained by the handicap principle (see section 9.7). Success for bandwagoning theory in accounting for the foregoing paradoxes (sections 3 through 8) also gives credibility to the notion that it can explain phenomena that are typically explained by established theory, such as the handicap principle.

Solon (2019; section 6.2) argued that genetic bandwagoning can accelerate the evolution of adaptations by directing resources from genotypes associated with a long-term fitness disadvantage to genotypes associated with a long-term fitness advantage, which accelerates the fixation of the alleles at other loci that are responsible for this long-term fitness advantage. Both resonation and reservation can have this effect.

Additionally, by increasing exposure and susceptibility to parasites and predators, a bandwagoning variant may exert a reverse effect upon these natural enemy populations. Just as reservation of ability against predators or parasites makes it more difficult for reserving organisms to survive against these natural enemies, it also makes the challenge of predating and parasitizing easier for the predators and parasites. This point is most salient to the evolution of predator populations. Poorly-adapted organisms of a predator population might have no success at

\footnotetext{
${ }^{7}$ Females would be more likely to engage in resonation (see prediction 4; section 9.8). However, a downregulation of resonation, which would be expected to lead to greater female fecundity, would typically not be identified in studies as a "benefit" of hormesis to females compared to males because it would also increase the reproductive success of males.
} 
capturing prey that do not reserve but might be able to successfully capture prey that reserve from their ability to survive predators, which would allow those predators to reproduce. Then the adaptations held by the best-adapted predators would gain frequency more slowly that if reservation had not been undertaken. In this manner, a bandwagoning variant that induces reservation from ability that is used against a natural enemy population can act to slow the evolution of adaptations within that natural enemy population.

This may be relevant to a problem that famously baffled Wynne-Edwards (1962): What prevents the overpopulation of predators in natural populations? When organisms increase their exposure, and susceptibility, to predators, this accelerates the evolution of the adaptations used to evade predators, while simultaneously slowing the evolution in the predator populations of adaptations used to pursue prey (the prey being the focus population). This may help explain cases in which a focus population "stays ahead" of its predators (e.g., Sutrisno et al., 2014), as the predators stay ahead of their own predators.

\section{Acknowledgements}

The manuscript is dedicated to Leonard R. Solon (1925-2018), a WW II veteran, physicist, and grandfather. I thank Josh Mitteldorf for feedback that enhanced the manuscript's clarity.

\section{References}

Agrawal, A.A. 2000. Overcompensation of plants in response to herbivory and the by-product benefits of mutualism. Trends Plant Sci., 5: 309-313.

Agren, J., Danell, K., Elmqvist, T., Ericson, L. and Hjalten, J. 1999. Sexual dimorphism and biotic interactions. In Gender and Sexual Dimorphism in Flowering Plants (Geber, M.A., Dawson, T.E. and Delph, L.F., eds.), pp. 217-246. Berlin: Springer-Verlag.

Alleva, E., Caprioli, A. and Laviola, G. 1989. Litter gender composition affects maternal behavior of the primiparous mouse dam (Mus musculus). J. Comp. Psychol., 103: 83-87.

Anders, S., Tanaka, M. and Kinney, D.K. 2013. Depression as an evolutionary strategy for defense against infection. Brain Behav. Immun., 31: 9-22.

Andersson, M. 1994. Sexual Selection. Princeton, NJ: Princeton University Press. 
Andrews, P.W. and Thomson, J.A., Jr. 2009. The bright side of being blue: depression as an adaptation for analyzing complex problems. Psychol. Rev., 116: 620-654.

Austin, M.P., Mitchell, P. and Goodwin, G.M. 2001. Cognitive deficits in depression: possible implications for functional neuropathology. Br. J. Psychiatry, 178: 200-206.

Ayers, L.W., Asok, A., Blaze, J., Roth, T.L. and Rosen, J.B. 2016. Changes in dam and pup behavior following postnatal exposure to a predator odor (TMT): a preliminary investigation in Long-Evans rats. Dev. Psychobiol., 58: 176-184.

Ayyanath, M.M., Cutler, G.C., Scott-Dupree, C.D., Prithviraj, B., Kandasamy, S. and Prithiviraj, K. 2014. Gene expression during imidacloprid-induced hormesis in green peach aphid. Dose-Response, 12: 480-497.

Ayyanath, M.M., Cutler, G.C., Scott-Dupree, C.D. and Sibley, P.K. 2013. Transgenerational shifts in reproductive hormesis in green peach aphid exposed to low concentrations of imidacloprid. PLOS One, 8: e74532.

Banta, J.A., Stevens, M.H.H. and Pigliucci, M. 2010. A comprehensive test of the "limiting resources" framework applied to plant tolerance to apical meristem damage. Oikos, 119: 359-369.

Barka, E.A., Nowak, J. and Clement, C. 2006. Enhancement of chilling resistance of inoculated grapevine plantlets with a plant growth-promoting rhizobacterium, Burkholderia phytofirmans strain PsJN. Appl. Environ. Microbiol., 72: 7246-7252.

Bateman, A.J. 1948. Intra-sexual selection in Drosophila. Heredity, 2: 349-368.

Belsky, A.J. 1986. Does herbivory benefit plants? A review of the evidence. Am. Nat., 127: 870-892.

Belsky, A.J., Carson, W.P., Jensen, C.L. and Fox, G.A. 1993. Overcompensation by plants: herbivore optimization or red herring? Evol. Ecol., 7: 109-121.

Berardi, A.E., Frey, F.M., Denton, E.M. and Wells, J.H. 2013. Betalain color morphs exhibit differential growth, defensive ability, and pollen tube growth rates in Mirabilis jalapa (Nyctaginaceae). Int. J. Plant Sci., 174: $1229-1238$. 
Berendsen, R.L., Pieterse, C.M. and Bakker, P.A. 2012. The rhizosphere microbiome and plant health. Trends Plant Sci., 17: 478-486.

Bolund, E., Schielzeth, H. and Forstmeier, W. 2009. Compensatory investment in zebra finches: females lay larger eggs when paired to sexually unattractive males. Proc. R. Soc. Lond. B: Biol. Sci., 276: 707-715.

Bortolini, M.J.S., Silva, M.V., Alonso, F.M., Medeiros, L.A., Carvalho, F.R., Costa, L.F., Silva, N.E., Penha-Silva, N., Mineo, T.W.P. and Mineo, J.R. 2016. Strength and aerobic physical exercises are able to increase survival of Toxoplasma gondii-infected C57BL/6 mice by interfering in the IFN-y expression. Front. Physiol., 7: 1-12.

Bosch, O.J., Musch, W., Bredewold, R., Slattery, D.A. and Neumann, I. 2007. Prenatal stress increases HPA axis activity and impairs maternal care in lactating female offspring: implications for postpartum mood disorder. Psychoneuroendocrinology, 32: 267-278.

Bredy, T.W., Humpartzoomian, R.A., Cain, D.P. and Meaney, M.J. 2003. Partial reversal of the effects of maternal care on cognitive function through environmental enrichment. Neuroscience, 118: 571-576.

Bredy, T.W., Zhang, T.Y., Grant, R.J., Diorio, J. and Meaney, M.J. 2004. Peripubertal environmental enrichment reverses the effects of maternal care on hippocampal development and glutamate receptor subunit expression. Eur. J. Neurosci., 20: 1355-1362.

Brenner, I.K.M., Shek, P.N. and Shephard, R.J. 1994. Infection in athletes. Sports Med., 17: 86-107.

Brilman, E.I. and Ormel, J. 2001. Life events, difficulties and onset of depressive episodes in later life. Psychol. Med., 31: 859-869.

Brockhurst, M.A., Chapman, T., King, K.C., Mank, J.E., Paterson, S. and Hurst, G.D.D. 2014. Running with the Red Queen: the role of biotic conflicts in evolution. Proc. R. Soc. Lond. B: Biol. Sci., 281: 20141382.

Brumm, H., Zollinger, S.A. and Slater, P.J.B. 2009. Developmental stress affects song learning but not song complexity and vocal amplitude in zebra finches. Behav. Ecol. Sociobiol., 63: 1387-1395.

Burger, J.M. 1995. Individual differences in preference for solitude. J. Res. Pers., 29: 85-108. 
Calabrese, E.J. 2005. Hormetic dose-response relationships in immunology: occurrence, quantitative features of the dose response, mechanistic foundations, and clinical implications. Crit. Rev. Toxicol., 35: 89-295.

Calabrese, E.J. 2010. Hormesis: once marginalized, evidence now supports hormesis as the most fundamental dose response. In Hormesis: A Revolution in Biology, Toxicology and Medicine (Mattson, M., Calabrese, E., eds.), pp. 15-56. New York: Springer.

Calabrese, E.J. 2013a. Biphasic dose responses in biology, toxicology and medicine: accounting for their generalizability and quantitative features. Environ. Pollut., 182: 452-460.

Calabrese, E.J. 2013b. Hormetic mechanisms. Crit. Rev. Toxicol., 43: 580-606.

Calabrese, E.J. and Baldwin, L.A. 2000. The marginalization of hormesis. Hum. Exp. Toxicol., 19: 32-40.

Calabrese, E.J. and Baldwin, L.A. 2001. Hormesis: U-shaped dose responses and their centrality in toxicology. Trends Pharmacol. Sci., 22: 285-291.

Calabrese, E.J. and Blain, R.B. 2011. The hormesis database: the occurrence of hormetic dose responses in the toxicological literature. Regul. Toxicol. and Pharmacol. 61: 73-81.

Calabrese, V., Cornelius, C., Dinkova-Kostova, A.T., Iavicoli, I., Di Paola, R., Koverech, A., Cuzzocrea, S., Rizzarelli, E. and Calabrese, E.J. 2012. Cellular stress responses, hormetic phytochemicals and vitagenes in aging and longevity. Biochim. Biophys. Acta, 1822: 753-783.

Caspi, A., Sugden, K., Moffitt, T.E., Taylor, A., Craig, I.W., Harrington, H., McClay, J., Mill, J., Martin, J., Braithwaite, A. and Poulton, R. 2003. Influence of life stress on depression: moderation by a polymorphism in the 5-HTT gene. Science, 301: 386-389.

Cavigelli, S.A. and Chaudhry, H.S. 2012. Social status, glucocorticoids, immune function, and health: can animal studies help us understand human socioeconomic-status-related health disparities? Horm. Behav., 62: 295313.

Chak, S.T.C., Duffy, J.E. and Rubenstein, D.R. 2015. Reproductive skew drives patterns of sexual dimorphism in sponge-dwelling snapping shrimps. Proc. R. Soc. Lond. B: Biol. Sci., 282: 20150342. 
Champagne, F.A., Francis, D.D., Mar, A. and Meaney, M.J. 2003. Variations in maternal care in the rat as a mediating influence for the effects of environment on development. Physiol. Behav., 79: 359-371.

Champagne, F.A. and Meaney, M.J. 2006. Stress during gestation alters postpartum maternal care and the development of the offspring in a rodent model. Biol. Psychiatry, 59: 1227-1235.

Clutton-Brock, T.H. 1984. Reproductive effort and terminal investment in iteroparous animals. Am. Nat., 123: 212229.

Clutton-Brock, T.H., Hodge, S.J., Flower, T.P., Spong, G. and Young, A. 2010. Adaptive suppression of subordinate reproduction in cooperative mammals. Am. Nat., 176: 664-673.

Cook, R. and Calabrese, E.J. 2006. The importance of hormesis to public health. Environ. Health Perspect., 114: $1631-1635$.

Cooney, G.M., Dwan, K., Greig, C.A., Lawlor, D.A., Rimer, J., Waugh, F.R., McMurdo, M. and Mead, G.E. 2013. Exercise for depression. Cochrane Database Syst. Rev., 12: CD004366.

Cooney, L.J., van Klink, J.W., Hughes, N.M., Perry, N.B., Schaefer, H.M., Menzies, I.J. and Gould, K. 2012. Red leaf margins indicate increased polygodial content and function as visual signals to reduce herbivory in Pseudowintera colorata. New Phytol., 194: 488-497.

Cornelissen, T. and Stilling, P. 2005. Sex-biased herbivory: a meta-analysis of the effects of gender on plantherbivore interactions. Oikos, 111: 488-500.

Costantini, D. 2014. Oxidative Stress and Hormesis in Evolutionary Ecology and Physiology. Berlin: SpringerVerlag.

Costantini, D., Metcalfe, N.B. and Monaghan, P. 2010. Ecological processes in a hormetic framework. Ecol. Lett., 13: $1435-1447$.

Coutellier, L. and Wurbel, H. 2009. Early environmental cues affect object recognition memory in adult female but not male C57BL/6 mice. Behav. Brain. Res., 203: 312-315. 
Craft, L.L. and Perna, F.M. 2004. The benefits of exercise for the clinically depressed. Prim. Care Companion J. Clin. Psychiatry, 6: 104-111.

Cui, J., Yang, G., Pan, Z., Zhao, Y., Liang, X., Li, W. and Cai, L. 2017. Hormetic response to low-dose radiation: focus on the immune system and its clinical implications. Int. J. Mol. Sci., 18: 280.

Davis, S.L., Dudle, D.A., Nawrocki, J.R., Freestone, L.M., Konieczny, P., Tobin, M.B. and Britton, M.M. 2014. Sexual dimorphism of staminate- and pistillate-phase flowers of Saponaria officinalis (Bouncing bet) affects pollinator behavior and seed set. Plos One, 9: e93615.

Davison, G., Kehaya, C. and Wyn Jones, A. 2014. Nutritional and physical activity interventions to improve immunity. Am. J. Lifestyle Med., 10: 152-169.

de Catanzaro, D. 1981. Suicide and Self-damaging Behavior: A Sociobiological Perspective. New York: Academic Press.

de Catanzaro, D. 1984. Suicidal ideation and the residual capacity to promote inclusive fitness: a survey. Suicide Life Threat. Behav., 14: 75-87.

Denenberg, V.H. and Karas, G.G. 1959. Effects of differential infantile handling upon weight gain and mortality in the rat and mouse. Science, 130: 629-630.

Dickins, T.E. and Rahman, Q. 2012. The extended evolutionary synthesis and the role of soft inheritance in evolution. Proc. R. Soc. Lond. B: Biol. Sci., 279: 2913-2921.

Dietz, D.M., LaPlant, Q., Watts, E.L., Hodes, G.E., Russo, S.J., Feng, J., Oosting, R.S., Vialou, V. and Nestler, E.J. 2011. Paternal transmission of stress-induced pathologies. Biol. Psychiatry, 70: 408-414.

Dietz, D.M. and Nestler, E.J. 2012. From father to offspring: paternal transmission of depressive-like behaviors. Neuropsychopharmacology, 37: 311-312.

Dong, Q., Salva, A., Sottas, C.M., Niu, E., Holmes, M. and Hardy, M.P. 2004. Rapid glucocorticoid mediation of suppressed testosterone biosynthesis in male mice subjected to immobilization stress. J. Androl., 25: 973 981. 
Dowlati, Y., Herrmann, N., Swardfager, W., Liu, H., Sham, L., Reim, E.K. and Lanctot, K.L. 2010. A meta-analysis of cytokines in major depression. Biol. Psychiatry, 67: 446-457.

Drury, S.S., Sanchez, M.M. and Gonzalez, A. 2016. When mothering goes awry: challenges and opportunities for utilizing evidence across rodent, nonhuman primate and human studies to better define the biological consequences of negative early caregiving. Horm. Behav., 77: 182-192.

Duffield, K.R., Bowers, E.K., Sakaluk, S.K. and Sadd, B.M. 2017. A dynamic threshold model for terminal investment. Behav. Ecol. Sociobiol., 71: 185

Dyer, M.I., Turner, C.L. and Seastedt, T. 1993. Herbivory and its consequences. Ecol. Appl., 3: 10-16.

Ellis, B.J. 2004. Timing of pubertal maturation in girls: an integrated life history approach. Psychol. Bull., 130: 920958.

Emlen, D.J., Warren, I.A., Johns, A., Dworkin, I. and Lavine, L.C. 2012. A mechanism of extreme growth and reliable signaling in sexually selected ornaments and weapons. Science, 337: 860-864.

Fedurek, P., Slocombe, K.E., Enigk, D.K., Emery Thompson, M., Wrangham, R.W. and Muller, M.N. 2016. The relationship between testosterone and long-distance calling in wild male chimpanzees. Behav. Ecol. Sociobiol., 70: 659-672.

Field, J., Solis, C.R., Queller, D.C. and Strassmann, J.B. 1998. Social and genetic structure of paper wasp cofoundress associations: tests of reproductive skew models. Am. Nat., 151: 545-563.

Field, T.M., Schanberg, S.M., Scafidi, F., Bauer, C.R., Vega-Lahr, N., Garcia, R., Nystrom, J. and Kuhn, C.M. 1986. Tactile/kinesthetic stimulation effects on preterm neonates. Pediatrics, 77: 654-658.

Field, T.M. 1998. Touch therapy effects on development. Int. J. Behav. Dev., 22: 779-797.

Fisher, R.A. 1930. The Genetical Theory of Natural Selection. Oxford: Clarendon Press.

Folstad, I. and Karter, A.J. 1992. Parasites, bright males, and the immunocompetence handicap. Am. Nat., 139: 603622.

Forbes, V.E. 2000. Is hormesis an evolutionary expectation? Funct. Ecol., 14: 12-24. 
Franklin, T.B., Linder, N., Russig, H., Thony, B. and Mansuy, I.M. 2011. Influence of early stress on social abilities and serotonergic functions across generations in mice. PLOS One, 6: e21842.

Franklin, T.B., Russig, H., Weiss, I.C., Graff, J., Linder, N., Michalon, A., Vizi, S. and Mansuy, I.M. 2010. Epigenetic transmission of the impact of early stress across generations. Biol. Psychiatry, 68: 408-415.

Franklin, T.B., Saab, B.J. and Mansuy, I.M. 2012. Neural mechanisms of stress resilience and vulnerability. Neuron, 75: 747-761.

Georgiev, A.V., Muehlenbein, M.P., Prall, S.P., Emery Thompson, M. and Maestripieri, D. 2015. Male quality, dominance rank, and mating success in free-ranging rhesus macaques. Behav. Ecol., 26: 763-772.

Getty, T. 1998. Handicap signalling: when fecundity and viability do not add up. Anim. Behav., 56: 127-130.

Getty, T. 2006. Sexually selected signals are not similar to sports handicaps. Trends Ecol. Evol., 21: 83-88.

Ghaziuddin, M., Ghaziuddin, N. and Stein, G. 1990. Life events and the recurrence of depression. Can. J. Psychiatry, 35: 239-242.

Gleeson, M. 2007. Immune function in sport and exercise. J. Appl.Physiol., 103: 693-699.

Gorzelak, M.A., Asay, A.K., Pickles, B.J. and Simard, S.W. 2015. Inter-plant communication through mycorrhizal networks mediates complex adaptive behaviour in plant communities. AoB Plants, 7: plv050.

Gould, K.S., Davies, K.M. and Winefield, C. 2009. Anthocyanins: Biosynthesis, Functions, and Applications. New York: Springer-Verlag.

Gould, K.S., Jay-Allemand, C., Logan, B.A., Baissac, Y., Bidel, L.P.R. 2018. When are foliar anthocyanins useful to plants? Re-evaluation of the photoprotection hypothesis using Arabidopsis thaliana mutants that differ in anthocyanin accumulation. Environ. Exp. Bot., 154: 11-22.

Gowaty, P.A. 2008. Reproductive compensation. J. Evol. Biol., 21: 1189-1200.

Gowaty, P.A., Anderson, W.W., Bluhm, C.K., Drickamer, L.C., Kim, Y. and Moore, A.J. 2007. The hypothesis of reproductive compensation and its assumptions about mate preferences and offspring viability. Proc. Natl. Acad. Sci. U.S.A., 104: 15023-15027. 
Gowaty, P.A., Kim, Y.K. and Anderson, W.W. 2012. No evidence of sexual selection in a repetition of Bateman's classic study of Drosophila melanogaster. Proc. Natl. Acad. Sci. U.S.A., 109: 11740-11745.

Grafen, A. 1990. Biological signals as handicaps. J. Theor. Biol., 144: 517-546.

Groothuis, T.G., Muller, W., von Engelhardt, N., Carere, C. and Eising, C. 2005. Maternal hormones as a tool to adjust offspring phenotype in avian species. Neurosci. Biobehav. Rev., 29: 329-352.

Grose, J. 2011. Modelling and the fall and rise of the handicap principle. Biol. Philos., 26: 677-696.

Haberlandt, G. 1914. Physiological Plant Anatomy, $2^{\text {nd }}$ reprint edition (1990). New Delhi: Today and Tomorrow's Printers and Publishers.

Habig, B. and Archie, E.A. 2015. Social status, immune response and parasitism in males: a meta-analysis. Philos. Trans. R. Soc. Lond. B Biol. Sci., 370: 20140109.

Hacquemand, R., Jacquot, L. and Brand, G. 2012. Postnatal exposure to predator odor (TMT) enhances spatial learning in mice adulthood. Behav. Brain Res., 229: 113-117.

Haddi, K., Mendes, M.V., Barcellos, M.S., Lino-Neto, J., Freitas, H.L., Guedes, R.N.C. and Oliveira, E.E. 2016. Sexual success after stress? Imidacloprid-induced hormesis in males of the neotropical stink bug Euschistus heros. PLOS One, 11: e0156616.

Hagen, E.H. 2003. The bargaining model of depression. In Genetic and Cultural Evolution of Cooperation. (Hammerstein, P., ed.), pp. 97-123. Cambridge, MA: MIT Press.

Hao, Y., Huang, W., Nielsen, D.A. and Kosten, T.A. 2011. Litter gender composition and sex affect maternal behavior and DNA methylation levels of the Oprm1 gene in rat offspring. Front. Psychiatry, 2: 21.

Harrison, X.A., York, J.E., Cram, D.L., Hares, M.C. and Young, A.J. 2013. Complete reproductive skew within white-browed sparrow weaver groups despite outbreeding opportunities for subordinates of both sexes. Behav. Ecol. Sociobiol., 67: 1915-1929.

Hart, B.L. 1988. Biological basis of the behavior of sick animals. Neurosci. Biobehav. Rev., 12: 123-137. 
Hartung, J. 1981. Genome parliaments and sex with the red queen. In Natural Selection and Social Behaviour: Recent Research and New Theory (R.D. Alexander and D.W. Tinkle, eds), pp. 382-402. New York: Chiron Press.

Hatlestad, G.J. and Lloyd, A. 2015. The betalain secondary metabolic network. In Pigments in Fruits and Vegetables (Chen, C., ed.), pp. 127-140. New York: Springer Science.

Hauber, M.E. and Lacey, E.A. 2005. Bateman's principle in cooperatively breeding vertebrates: the effects of nonbreeding alloparents on variability in female and male reproductive success. Integr. Comp. Biol., 45: 903914.

Hauser, M.D. 1997. The Evolution of Communication. Cambridge, MA: MIT Press.

Heiming, R.S., Bodden, C., Jansen, F., Lewejohann, L., Kaiser, S., Lesch, K.P., Palme, R. and Sachser, N. 2011. Living in a dangerous world decreases maternal care: a study in serotonin transporter knockout mice. Horm. Behav., 60: 397-407.

Hernandez-Pando, R., Pavon, L., Arriaga, K., Orozco, H., Madrid-Marina, V. and Rook, G. 1997. Pathogenesis of tuberculosis in mice exposed to low and high doses of an environmental mycobacterial saprophyte before infection. Infect. Immun., 65: 3317-3327.

Hill, G.E. 2006. Environmental regulation of ornamental coloration. In Bird Coloration, Volume 1 (Hill, G.E. and McGraw, K.J., eds.), pp. 507-560. Cambridge, MA: Harvard University Press.

Hill, G.E. 2014. Cellular respiration: the nexus of stress, condition, and ornamentation. Integr. Comp. Biol., 54: 645657.

Hopcroft, R.L. and Bradley, D.B. 2007. The sex difference in depression across 29 countries. Soc. Forces, 85: 14831507.

Husak, J.F. and Swallow, J.G. 2011. Compensatory traits and the evolution of male ornaments. Behaviour, 148: 129.

Irving, G. and Lloyd-Williams, W. 2010. Depression in advanced cancer. Eur. J. Oncol. Nurs., 14: $395-399$. 
Iwakabe, K., Shimada, M., Ohta, A., Yahata, T., Ohmi, Y., Habu, S. and Nishimura, T. 1998. The restraint stress drives a shift in Th1/Th2 balance toward Th2-dominant immunity in mice. Immunol. Lett., 62: 39-43.

Jager, T., Barsi, A. and Ducrot, V. 2013. Hormesis on life-history traits: is there such thing as a free lunch? Ecotoxicology, 22: 263-270.

Jain, G. and Gould, K.S. 2015. Are betalain pigments the functional homologues of anthocyanins in plants? Environ. Exp. Bot., 119: 48-53.

Janicke, T., Haderer, I.K., Lajeunesse, M.J. and Anthes, N. 2016. Darwinian sex roles confirmed across the animal kingdom. Sci. Adv., 2: e1500983.

Johnstone, R.A. 1995. Sexual selection, honest advertisement and the handicap principle: reviewing the evidence. Biol. Rev. Camb. Philos. Soc., 70: 1-65.

Johnstone, R.A. 2000. Models of reproductive skew: a review and synthesis. Ethology, 106: 5-26.

Juenger, T. and Bergelson, J. 2000. The evolution of compensation to herbivory in scarlet gilia, Ipomopsis aggregata: herbivore-imposed natural selection and the quantitative genetics of tolerance. Evolution, 54: 764-777.

Kaltiala-Heino, R. and Frojd, S. 2011. Correlation between bullying and clinical depression in adolescent patients. Adolesc. Health Med. Ther., 2: 37-44.

Kankova, Z., Zeman, M. and Okuliarova, M. 2014. Selection for high egg testosterone and immune response of young Japanese quail under mild food restriction. Avian Biol. Res., 7: 25-32.

Karageorgou, P., Buschmann, C. and Manetas, Y. 2008. Red leaf color as a warning signal against insect herbivory: honest or mimetic? Flora, 203: 648-652.

Kendler, K.S., Thornton, L.M. and Gardner, C.O. 2000. Stressful life events and previous episodes in the etiology of major depression in women: an evaluation of the "kindling" hypothesis. Am. J. Psychiatry, 157: 1243-1251.

Kim, B., Song, G.C. and Ryu, C.M. 2016. Root exudation by aphid leaf infestation recruits root-associated Paenibacillus spp. to lead plant insect susceptibility. J. Microbiol. Biotechnol., 26: 549-557. 
Kinney, D.K. and Tanaka, M. 2009. An evolutionary hypothesis of depression and its symptoms, adaptive value, and risk factors. J. Nerv. Ment. Dis., 197: 561-567.

Klein, S.L. 2000. The effects of hormones on sex differences in infection: from genes to behavior. Neurosci. Biobehav. Rev., 24: 627-638.

Kong, H.G., Kim, B.K., Song, G.C., Lee, S. and Ryu, C.M. 2016. Aboveground whitefly infestation-mediated reshaping of the root microbiota. Front. Microbiol., 7: 1314.

Korosi, A. and Baram, T.Z. 2009. The pathways from mother's love to baby's future. Front. Behav. Neurosci., 3: 27.

Kovinich, N., Kayanja, G., Chanoca, A., Riedl, K., Otegui, M.S. and Grotewold, E. 2014. Not all anthocyanins are born equal: distinct patterns induced by stress in Arabidopsis. Planta 240: 931-940.

Krogh, J., Hjorthoj, C., Speyer, H., Gluud, C. and Nordentoft, M. 2017. Exercise for patients with major depression: a systematic review with meta-analysis and trial sequential analysis. BMJ Open, 7: e014820.

Lagrange, P.H., Mackaness, G.B. and Miller, T.E. 1974. Influence of dose and route of antigen injection on the immunological induction of T cells. J. Exp. Med., 139: 528-542.

Lampe, J.W. 1999. Health effects of vegetables and fruit: assessing mechanisms of action in human experimental studies. Am. J. Clin. Nutr., 70: 475S-490S.

LeBourg, E. and Rattan, S.I. 2014. Hormesis and trade-offs: a comment. Dose-Response, 12: 522-524.

Lee, B., Lee, S. and Ryu, C.M. 2012. Foliar aphid feeding recruits rhizosphere bacteria and primes plant immunity against pathogenic and non-pathogenic bacteria in pepper. Ann. Bot., 110: 281-290.

Lee, K.A. 2006. Linking immune defenses and life history at the levels of the individual and the species. Integr. Comp. Biol., 46: 1000-1015.

Leitzmann, C. 2016. Characteristics and health benefits of phytochemicals. Complement. Med. Res., 23: 69-74.

Lennartsson, T., Tuomi, J. and Nilsson, P. 1997. Evidence for an evolutionary history of overcompensation in the grassland biennial Gentianella campestris (Gentianaceae). Am. Nat., 149: 1147-1155. 
Liow, L.H., Van Valen, L. and Stenseth, N.C. 2011. Red Queen: from populations to taxa and communities. Trends Ecol. Evol., 26: 349-358.

Liu, D., Caldji, C., Sharma, S., Plotsky, P.M. and Meaney, M.J. 2000. Influence of neonatal rearing conditions on stress-induced adrenocorticotropin responses and norepinephrine release in the hypothalamic paraventricular nucleus. J. Neuroendocrinol., 12: 5-12.

Lively, C.M. 2011. The cost of males in non-equilibrium populations. Evol. Ecol. Res., 13: 105-111.

Lynn, S.E., Perfito, N., Guardado, D. and Bentley, G.E. 2015. Food, stress, and circulating testosterone: cue integration by the testes, not the brain, in male zebra finches (Taeniopygia guttata). Gen. Comp. Endocrinol., 215: 1-9.

Manetas, Y. 2006. Why some leaves are anthocyanic and why most anthocyanic leaves are red? Flora, 201: 163177.

Mansuy, I.M., Mashoodh, R. and Champagne, F.A. 2013. Transgenerational inheritance in mammals. In Epigenetic Regulation in the Nervous System: Basic Mechanisms and Clinical Impact (Sweatt, J.D., Meaney, M.J., Nestler, E.J. and Akbarian, S., eds.), pp. 323-338. London: Academic Press.

Mashoodh, R., Sinal, C.J. and Perrot-Sinal, T.S. 2009. Predation threat exerts specific effects on rat maternal behaviour and anxiety-related behaviour of male and female offspring. Physiol. Behav., 96: 693-702.

Mashoodh, R., Franks, B., Curley, J.P. and Champagne, F.A. 2012. Paternal social enrichment effects on maternal behavior and offspring growth. Proc. Natl. Acad. Sci. U.S.A., 109: 17232-17238.

Mattson, M.P. 2008a. Hormesis defined. Ageing Res. Rev., 7: 1-7.

Mattson, M.P. 2008b. Dietary factors, hormesis and health. Ageing Res. Rev., 7: 43-48.

McClure, C.D., Zhong, W., Hunt, V.L., Chapman, F.M., Hill, F.V. and Priest, N.K. 2014. Hormesis results in tradeoffs with immunity. Evolution, 68: 2225-2233. 
McGraw, K.J. and Blount, J. 2009. Control and function of carotenoid coloration in birds: selected case studies. In Carotenoids: Physical, Chemical, and Biological Functions and Properties (Landrum, J.T., ed.), pp. 487510. Boca Raton, FL: CRC Press.

McLeod, J., Sinal, C.J. and Perrot-Sinal, T.S. 2007. Evidence for non-genomic transmission of ecological information via maternal behavior in female rats. Genes Brain Behav., 6: 19-29.

Meaney, M.J. 2001. Maternal care, gene expression, and the transmission of individual differences in stress reactivity across generations. Annu. Rev. Neurosci., 24: 1161-1192.

Medawar, P.B. 1952. An Unsolved Problem of Biology. London: Lewis.

Menzies, I.J., Youard, L.W., Lord, J.M., Carpenter, K.L., van Klink, J.W., Perry, N.B., Schaefer, H.M. and Gould, K.S. 2016. Leaf colour polymorphisms: a balance between plant defence and photosynthesis. J. Ecol., 104: $104-113$.

Mesa, J.M., Scholes, D.R., Juvik, J.A. and Paige, K.N. 2017. Molecular constraints on resistance-tolerance tradeoffs. Ecology, 98: 2528-2537.

Miguel, M.G. 2018. Betalains in some species of the Amaranthaceae family: a review. Antioxidants, 7: 53.

Moore, C.L. 1995. Maternal contributions to mammalian reproductive development and the divergence of males and females. Adv. Study Behav., 24: 47-118.

Moore, C.L. and Chadwick-Dias, A.M. 1986. Behavioral responses of infant rats in maternal licking: variations with age and sex. Dev. Psychobiol., 19: 427-438.

Moore, C.L. and Morelli, G.A. 1979. Mother rats interact differently with male and female offspring. J. Comp. Physiol. Psychol., 93: 677-684.

Moore, C.L. and Power, K.L. 1986. Prenatal stress affects mother-infant interaction in Norway rats. Dev. Psychobiol., 19: 235-245.

Mucciarelli, M., Scannerini, S., Bertea, C. and Maffei, M. 2003. In vitro and in vivo peppermint (Mentha piperita) growth promotion by nonmycorrhizal fungal colonization. New Phytol., 158: 579-591. 
Muehlenbein, M.P. and Bribiescas, R.G. 2005. Testosterone-mediated immune functions and male life histories. Am. J. Hum. Biol., 17: 527-558.

Mushak, P. 2009. Ad hoc and fast forward: the science of hormesis growth and development. Environ. Health Perspect., 117: 1333-1338.

Navara, K.J., Badyaev, A.V., Mendonca, M.T. and Hill, G.E. 2006. Yolk antioxidants vary with male attractiveness and female condition in the house finch (Carpodacus mexicanus). Physiol. Biochem. Zool., 79: 1098-1105.

Naylor, D. and Coleman-Derr, D. 2017. Drought stress and root-associated bacterial communities. Front. Plant. Sci., 8: 2223 .

Nelson, R.J., Frank, D., Bennett, S.A. and Carter, C.S. 1989. Simulated drought influences reproduction in male prairie voles. Physiol. Behav., 46: 849-852.

Nestler, E.J. 2012. Epigenetics: stress makes its molecular mark. Nature, 490: 171-172.

Nestler, E.J. 2014. Epigenetic mechanisms of depression. JAMA Psychiatry, 71: 454-456.

Nettle, D. 2004. Evolutionary origins of depression: a review and reformulation. J. Affect. Disord., 81: 91-102.

Nieman, D.C. 1998. Exercise and resistance to infection. Can. J. Physiol. Pharmacol., 76: 573-580.

Nolen-Hoeksema, S. 1990. Sex Differences in Depression. Stanford, CA: Stanford University Press.

Nonacs, P. and Hager, R. 2011. The past, present and future of reproductive skew theory and experiments. Biol. Rev. Camb. Philos. Soc., 86: 271-298.

Obeso, J.R. 2002. The costs of reproduction in plants. New Phytol., 155: 321-348.

Paige, K.N. 1999. Regrowth following ungulate herbivory in Ipomopsis aggregata: geographic evidence for overcompensation. Oecologia, 118: 316-323.

Paige, K.N. and Whitham, T.G. 1987. Overcompensation in response to mammalian herbivory: the advantage of being eaten. Am. Nat., 129: 407-416.

Parish, C.R. 1972. The relationship between humoral and cell-mediated immunity. Transplant Rev., 13: 35-66. 
Parker, G. and Brotchie, H. 2017. Pancreatic cancer and depression: a narrative review. J. Nerv. Ment. Dis., 205: 487-490.

Pittet, F., Coignard, M., Houdelier, C., Richard-Yris, M.A. and Lumineau, S. 2012. Age affects the expression of maternal care and subsequent behavioural development of offspring in a precocial bird. PLOS One, 7: e36835.

Polturak, G. and Aharoni, A. 2018. "La vie en rose": biosynthesis, sources, and applications of betalain pigments. Mol. Plant., 11: 7-22.

Pryce, C.R. and Fontana, A. 2017. Depression in autoimmune diseases. Curr. Top. Behav. Neurosci., 31: 139-154.

Raison, C.L. and Miller, A.H. 2013. The evolutionary significance of depression in Pathogen Host Defense (PATHOS-D). Mol. Psychiatry, 18: 15-37.

Ram, Y. and Hadany, L. 2016. Condition-dependent sex: who does it, when and why? Philos. Trans. R. Soc. Lond. B Biol. Sci., 371: 20150539.

Ramchandani, P., Stein, A., Evans, J. and O'Connor, T.G. 2005. Paternal depression in the postnatal period and child development: a prospective population study. Lancet 365: 2201-2205.

Ratikainen, I.I. and Kokko, H. 2010. Differential allocation and compensation: who deserves the silver spoon? Behav. Ecol., 21: 195-200.

Rattan, S.I. 2008. Hormesis in aging. Ageing Res. Rev., 7: 63-78.

Rattan, S.I. and Demirovic, D. 2010. Hormesis can and does work in humans. Dose-Response, 8: 58-63.

Ridley, M. 1993. The Red Queen: Sex and the Evolution of Human Nature. New York: Macmillan.

Ritschard, M., Laucht, S., Dale, J. and Brumm, H. 2011. Enhanced testosterone levels affect singing motivation but not song amplitude in Bengalese finches. Physiol. Behav., 102: 30-35.

Ritschard, M., Riebel, K. and Brumm, H. 2010. Female zebra finches prefer high-amplitude song. Anim. Behav., 79: 877-883. 
Roberts, M.L., Buchanan, K.L. and Evans, M.R. 2004. Testing the immunocompetence handicap hypothesis: a review of the evidence. Anim. Behav., 68: 227-239.

Rubenstein, D.R. and Lovette, I.J. 2009. Reproductive skew and selection on female ornamentation in social species. Nature, 462: 786-789.

Sadikoglu, N. and Cevahir, G. 2004. Anthocyanin content and localization in different parts of Trachystemon orientalis (L.) G. Don. Biotechnol. Biotechnol. Equip., 18: 119-123.

Safran, R.J., Pilz, K.M., McGraw, K.J., Correa, S.M. and Schwabl, H. 2008. Are yolk androgens and carotenoids related to parental quality? Behav. Ecol. Sociol., 62: 427-438.

Saino, N., Bertacche, V., Ferrari, R.P., Martinelli, R., Moller, A.P. and Stradi, R. 2002. Carotenoid concentration in barn swallow eggs is influenced by laying order, maternal infection and paternal ornamentation. Proc. $R$. Soc. Lond. B., 269: 1729-1733.

Saltzman, W., Digby, L.J. and Abbott, D.H. 2009. Reproductive skew in female common marmosets: what can proximate mechanisms tell us about ultimate causes? Proc. R. Soc. Lond. B: Biol. Sci., 276: 389-399.

Salvin, S.B. 1958. Occurrence of delayed hypersensitivity during the development of Arthus type hypersensitivity. J. Exp. Med., 107: 109-124.

Sapolsky, R.M. 1998. Why Zebras Don't Get Ulcers, $2^{\text {nd }}$ edition. New York: W.H. Freeman and Company.

Sapolsky, R.M. 2001. Physiological and pathophysiological implications of social stress in mammals. In Handbook of Physiology: Section 7, The Endocrine System; Volume IV: Coping with the Environment (McEwen, B., ed.), pp. 517-532. Oxford: Oxford University Press.

Schaefer, H.M. and Rolshausen, G. 2006. Plants on red alert: do insects pay attention? BioEssays, 28: 65-71.

Schanberg, S. 1995. The genetic basis for touch effects. In Touch in Early Development (Field, T., ed.), pp. 67-80. New York: Psychology Press.

Schreiber, S.J. 2015. Unifying within- and between-generation bet-hedging theories: an ode to J.H. Gillespie. Am. Nat., 186: 792-796. 
Schuch, F.B., Vancampfort, D., Richards, J., Rosenbaum, S., Ward, P.B. and Stubbs, B. 2016. Exercise as a treatment for depression: a meta-analysis adjusting for publication bias. J. Psychiatr. Res., 77: 42-51.

Seedat, S., Scott, K.M., Angermeyer, M.C., Berglund, P., Bromet, E.J., Brugha, T.S., Demyttenaere, K., de Girolamo, G., Haro, J.M., Jin, R., Karam, E.G., Kovess-Masfety, V., Levinson, D., Medina Mora, M.E., Ono, Y., Ormel, J., Pennell, B.E., Posada-Villa, J., Sampson, N.A., Williams, D. and Kessler, R.C. 2009. Cross-national associations between gender and mental disorders in the World Health Organization World Mental Health Surveys. Arch. Gen. Psychiatry, 66: 785-795.

Seligman, M.E.P. 1975. Helplessness: On Depression, Development, and Death. San Francisco: W.H. Freeman and Company.

Serrano-Diaz, J., Sanchez, A.M., Maggi, L., Martinez-Tome, M., Garcia-Diz, L., Murcia, M.A. and Alonso, G.L. 2012. Increasing the applications of Crocus sativus flowers as natural antioxidants. J. Food Sci., 77: C1162-C1168.

Shen, H., Magnusson, C., Rai, D., Lundberg, M., Le-Scherban, F., Dalman, C. and Lee, B.K. 2016. Associations of parental depression with child school performance at age 16 years in Sweden. JAMA Psychiatry, 73: 239246.

Shephard, A.M., Aksenov, V., Tran, J., Nelson, C.J., Boreham, D.R. and Rollo, C.D. 2018. Hormetic effects of early juvenile radiation exposure on adult reproduction and offspring performance in the cricket (Acheta domesticus). Dose-Response, 16: 1559325818797499.

Shephard, R.J., Shek, P. N. and DiNubile, N.A. 1999. Exercise, immunity, and susceptibility to infection. Phys. Sportsmed., 27: 47-71.

Sih, A., Bell, A. and Johnson, J.C. 2004. Behavioral syndromes: an ecological and evolutionary overview. Trends Ecol. Evol., 19: 372-378.

Simard, S.W., Beiler, K.J., Bingham, M.A., Deslippe, J.R., Phillip, L.J. and Teste, F.P. 2012. Mycorrhizal networks: mechanisms, ecology and modeling. Fungal Biol. Rev., 26: 39-60. 
Simons, M.J.P., Groothuis, T.G.G. and Verhulst, S. 2015. An appraisal of how the vitamin A-redox hypothesis can maintain honesty of carotenoid-dependent signals. Ecol. Evol., 5: 224-228.

Simons, M.J.P., Maia, R., Leenknegt, B. and Verhulst, S. 2014. Carotenoid-dependent signals and the evolution of plasma carotenoid levels in birds. Am. Nat., 184: 741-751.

Singh, N., Yadav, A. and Varma, A. 2015. Effect of plant growth promoting activity of rhizobacteria on cluster bean (Cyamopsis tetragonoloba L.) plant growth and biochemical constituents. Int. J. Curr. Microbiol. App. Sci., 4: 1071-1082.

Smith, J.W., Seckl, J.R., Evans, A.T., Costall, B. and Smythe, J.W. 2004. Gestational stress induces post-partum depression-like behaviour and alters maternal care in rats. Psychoneuroendocrinology, 29: 227-244.

Snyder, B.F. and Gowaty, P.A. 2007. A reappraisal of Bateman's classic study of intrasexual selection. Evolution, 61: $2457-2468$.

Solomon, D.A., Keller, M.B., Leon, A.C., Mueller, T.I., Lavori, P.W., Shea, M.T., Coryell, W., Warshaw, M., Turvey, C., Maser, J.D. and Endicott, J. 2000. Multiple recurrences of major depressive disorder. Am. J. Psychiatry, 157: 229-233.

Solon, I.S. 2019. The evolution of genetic bandwagoning. bioRiv doi: 10.1101/064493

Song, Y.Y., Simard, S.W., Carroll, A., Mohn, W.W. and Sen Zeng, R. 2015. Defoliation of interior Douglas-fir elicits carbon transfer and stress signalling to ponderosa pine neighbors through ectomycorrhizal networks. Sci. Rep., 5: 8495.

Sorensen, J.G., Kristensen, T.N., Kristensen, K.V. and Loeschcke, V. 2007. Sex specific effects of heat induced hormesis in Hsf-deficient Drosophila melanogaster. Exp. Gerontol., 42: 1123-1129.

Stathopoulou, G., Powers, M.B., Berry, A.C., Smits, J.A. and Otto, M.W. 2006. Exercise interventions for mental health: a quantitative and qualitative review. Clin. Psychol. Sci. Pract., 13: 179-193.

St-Cyr, S., Abuaish, S., Sivanathan, S. and McGowan, P.O. 2017. Maternal programming of sex-specific responses to predator odor stress in adult rats. Horm. Behav., 94: 1-12. 
St-Cyr, S., Abuaish, S., Welch, Jr., K.C. and McGowan, P.O. 2018. Maternal predator odour exposure programs metabolic responses in adult offspring. Sci. Rep., 8: 8077.

St-Cyr, S. and McGowan, P.O. 2015. Programming of stress-related behavior and epigenetic neural gene regulation in mice offspring through maternal exposure to predator odor. Front. Behav. Neurosci., 9: 145.

Steyn, W.J., Wand, S.J.E., Holcroft, D.M. and Jacobs, G. 2002. Anthocyanins in vegetative tissues: a proposed unified function in photoprotection. New Phytol., 155: 349-361.

Strauss, S.Y. and Whittall, J.B. 2006. Non-pollinator agents of selection on floral traits. In Ecology and Evolution of Flowers (Harder, L.D. and Barrett, S.C.H., eds.), pp. 120-138. New York: Oxford.

Sun, H., Kennedy, P.J. and Nestler, E.J. 2013. Epigenetics of the depressed brain: role of histone acetylation and methylation. Neuropsychopharmacology, 38: 124-137.

Suomi, S.J. 1997. Early determinants of behaviour: evidence from primate studies. Br. Med. Bull., 53: 170-184.

Sutrisno, R., Schotte, P.M. and Wisenden, B.D. 2014. Chemical arms race between predator and prey: a test of predator digestive countermeasures against chemical labeling by dietary cues of prey. J. Freshw. Ecol., 29: $17-23$.

Takahashi, L.K., Nakashima, B.R., Hong, H. and Watanbe, K. 2005. The smell of danger: A behavioral and neural analysis of predator odor-induced fear. Neurosci. Biobehav. Rev., 29: 1157-1167.

Tang-Martinez, Z. 2016. Rethinking Bateman's principles: challenging persistent myths of sexually reluctant females and promiscuous males. J. Sex Res., 53: 532-559.

Teste, F., Simard, S., Durall, D.M., Guy, R.D., Jones, M.D. and Schoonmaker, A.L. 2009. Access to mycorrhizal networks and roots of trees: importance for seedling survival and resource transfer. Ecology, 90: 28082022.

Thayer, K.A., Melnick, R., Burns, K., Davis, D. and Huff, J. 2005. Fundamental flaws of hormesis for public health decisions. Environ. Health Perspect., 113: 1271-1276. 
Trivers, R.L. 1972. Parental investment and sexual selection. In Sexual Selection and the Descent of Man, 1871 1971 (Campbell, B.G., ed.), pp. 136-179. Chicago: Aldine.

Vallejo-Marin, M. and Rausher, M.D. 2007. Selection through female fitness helps to explain the maintenance of male flowers. Am. Nat., 169: 563-568.

Van der Vegt, E.J., Van der Ende, J., Ferdinand, R.F., Verhulst, F.C. and Tiemeier, H. 2009. Early childhood adversities and trajectories of psychiatric problems in adoptees: evidence for long lasting effects. $J$. Abnorm. Child Psychol., 37: 239-249.

Van Hasselt, F. N., Tieskens, J. M., Trezza, V., Krugers, H. J., Vanderschuren, L. J. M. J. and Joëls, M. 2012. Within-litter variation in maternal care received by individual pups correlates with adolescent social play behavior in male rats. Physiol. Behav., 106: 701-706.

Van Valen, L. 1973. A new evolutionary law. Evol. Theory, 1: 1-30.

Varga, S. 2012. Evolutionary psychiatry and depression: testing two hypotheses. Med. Health Care Philos., 15: 4152.

Vargas-Hernandez, M., Macias-Bobadilla, I., Guevara-Gonzalez, R.G., Romero-Gomez, S. de J., Rico-Garcia, E., Ocampo-Velazquez, R.V., Alvarez-Arquieta, L. de L. and Torres-Pacheco, I. 2017. Plant hormesis management with biostimulants of biotic origin in agriculture. Front. Plant. Sci., 8: 1762.

Vehrencamp, S.L. 1983. A model for the evolution of despotic versus egalitarian societies. Anim. Behav., 31: 667682.

Weaver, R.J., Koch, R.E. and Hill, G.E. 2017. What maintains signal honesty in animal colour displays used in mate choice? Philos. Trans. R. Soc. Lond. B Biol. Sci., 372: 20160343.

Weiss, I.C., Franklin, T.B., Vizi, S. and Mansuy, I.M. 2011. Inheritable effect of unpredictable maternal separation on behavioral responses in mice. Front. Behav. Neurosci., $5: 3$.

Weiss, J.M., Bailey, W.H., Goodman, P.A., Hoffman, L.J., Ambrose, M.J., Salman, S. and Charry, J.M. 1982. A model for neurochemical study of depression. In Behavioral Models and the Analysis of Drug Action (Spiegelstein, M.Y. and Levy, A., eds.), pp. 195-223. Amsterdam: Elsevier Scientific Publishing Company. 
Widom, C.S., DuMont, K. and Czaja, S.J. 2007. A prospective investigation of major depressive disorder and comorbidity in abused and neglected children grown up. Arch. Gen. Psychiatry, 64: 49-56.

Williams, G.C. 1966. Natural selection, the costs of reproduction, and a refinement of Lack's Principle. Am. Nat., 100: $687-690$.

Wortis, H.H., Taylor, R.B., Dresser, D.W. 1966. Antibody production studied by means of the LHG assay splenic response of CBA mice to sheep erythrocytes. Immunology, 11: 603-616.

Wynne-Edwards, V.C. 1962. Animal Dispersion in Relation to Social Behaviour. Edinburgh: Oliver and Boyd. Yamamoto, M.E., Araujo, A., de Fatima Arruda, M., Moreira Lima, A.K., de Oliveira Siqueira, J. and Tadashi Hattori, W. 2014. Male and female breeding strategies in a cooperative primate. Behav. Process., 109: 2733.

Yang, G., Li, W., Jiang, H., Liang, X., Zhao, Y., Yu, D., Zhou, L., Wang, G., Tian, H., Han, F., Cai, L. and Cui, J. 2016. Low-dose radiation may be a novel approach to enhance the effectiveness of cancer therapeutics. Int. J. Cancer, 139: 2157-2168.

Yang, J.W., Yi, H.S., Kim, H., Lee, B., Lee, S., Ghim, S.Y. and Ryu, C.M. 2011. Whitefly infestation of pepper plants elicits defence responses against bacterial pathogens in leaves and roots and changes the belowground microflora. J. Ecol., 99: 46-56.

Yirmiya, R., Weidenfeld, J., Pollak, Y., Morag, M., Morag, A., Avitsur, R., Barak, O., Reichenberg, A., Cohen, E., Shavit, Y. and Ovadia, H. 1999. Cytokines, "depression due to a general medical condition,” and antidepressant drugs. In Cytokines, Stress, and Depression. Advances in Experimental Medicine and Biology, Volume 461 (Dantzer, R., Wollman, E.E. and Yirmiya, R., eds.), pp. 283-316. New York: Springer.

Young, A.J. and Bennett, N.C. 2013. Intra-sexual selection in cooperative mammals and birds: why are females not bigger and better armed? Philos. Trans. R. Soc. Lond. B Biol. Sci., 368: 20130075.

Zahavi, A. 1975. Mate selection-A selection for a handicap. J. Theor. Biol., 53: 205-214. 
Zahavi, A. and Zahavi, A. 1997. The Handicap Principle: A Missing Piece of Darwin's Puzzle. Oxford: Oxford University Press.

Zann, R. and Cash, E. 2008. Developmental stress impairs song complexity but not learning accuracy in nondomesticated zebra finches (Taeniopygia guttata). Behav. Ecol. Sociobiol., 62: 391-400.

Zhang, T.Y. and Meaney, M.J. 2010. Epigenetics and the environmental regulation of the genome and its function. Annu. Rev. Psychol., 61: 439-466.

Zhang, T. and Tan, D.Y. 2009. An examination of the function of male flowers in an andromonoecious shrub Capparis spinosa. J. Integr. Plant Biol., 51: 316-324.

Zollinger, S.A., Goller, F. and Brumm, H. 2011. Metabolic and respiratory costs of increasing song amplitude in zebra finches. PLOS One 6: e23198.

Zuk, M. 1990. Reproductive strategies and disease susceptibility: an evolutionary viewpoint. Parasitol. Today, 6 : 231-233. 